\title{
1. A numerical study of SMART Cables potential in marine hazard early warning for the Sumatra and Java regions
}

\author{
Amir Salaree ${ }^{1}$ \\ Department of Earth and Environmental Sciences \\ University of Michigan \\ 1100 N University Ave, Ann Arbor, MI 48109 \\ Bruce M. Howe ${ }^{2}$ \\ Department of Ocean and Resources Engineering (SOEST) \\ University of Hawaii at Mānoa \\ 2540 Dole St, Honolulu, HI 96822 \\ Yihe Huang ${ }^{3}$ \\ Department of Earth and Environmental Sciences \\ University of Michigan \\ 1100 N University Ave, Ann Arbor, MI 48109 \\ Stuart A. Weinstein ${ }^{4}$ \\ Pacific Tsunami Warning Center \\ National Oceanic and Atmospheric Administration \\ 1845 Wasp Boulevard, Building 176, Honolulu, HI 96818 \\ Andi Eka Sakya ${ }^{5}$ \\ Agency for the Assessment and Application of Technology (BPPT) \\ Jl. M.H Thamrin No. 8 Jakarta Pusat DKI Jakarta 10340
}

April 30, 2021

for submission to

Natural Hazards

This is a non-peer reviewed preprint submitted to EarthArXiv.

\footnotetext{
${ }^{1}$ salaree@umich.edu

${ }^{2}$ bhowe@hawaii.edu

3 yiheh@umich.edu

${ }^{4}$ stuart.weinstein@noaa.gov

${ }^{5}$ andi.eka@bppt.go.id
} 


\begin{abstract}
We present results from a series of exploratory numerical experiments based on ocean bottom pressure and seismic data from a simulated linear array of SMART cable stations off the trench in the Sumatra-Java region. We use six rupture scenarios to calculate tsunami propagation using hydrodynamic simulations. Through these experiments we show that such an addition would result in up to several hours of improvement in the detection of earthquakes and tsunamis compared to the existing (minimal) DART system in the Indian Ocean. By simulating tsunamis from 58 submarine landslide scenarios in the region, we show that the SMART system can provide invaluable information in early warning against landslide tsunamis. We also calculate seismic phase arrival times from the six source scenarios at the existing seismic stations and our proposed SMART cables. Statistical analysis of our results shows that inclusion of such a SMART array can improve the important network parameters for the detection, evaluation and locating of seismic events.
\end{abstract}

${ }_{41}$ Keywords: SMART Cables, Tsunami, Earthquake, Landslide, Early warning, In42 donesia 


\section{${ }_{43} 1$ Introduction}

44

45

46

47

48

49

The ubiquitous integration of environmental sensors into the repeaters of submarine telecommunication cables for planetary scale Scientific Monitoring And Reliable Telecommunications (SMART) has been proposed with implementation just now starting (Howe et al., 2019).

Such systems must be part of the larger national and international multi-hazard warning networks, providing necessary data for seismic, tsunami, volcano and other early warning scenarios. Further, the system must necessarily provide ocean and climate measurements to serve the regional and the international community, i.e., it must be a multi-purpose system. This is reinforced by a recommendation from the OceanObs'19 conference: "Transition telecom+sensing SMART subsea cable systems from present pilots to trans-ocean and global implementation, to support climate, ocean circulation, sea level monitoring, and tsunami and earthquake early warning and disaster risk reduction." (OceanObs'19, 2019). The global distribution of subsea telecom cables in Fig. 1 show the potential of trans-oceanic networks in this respect. 

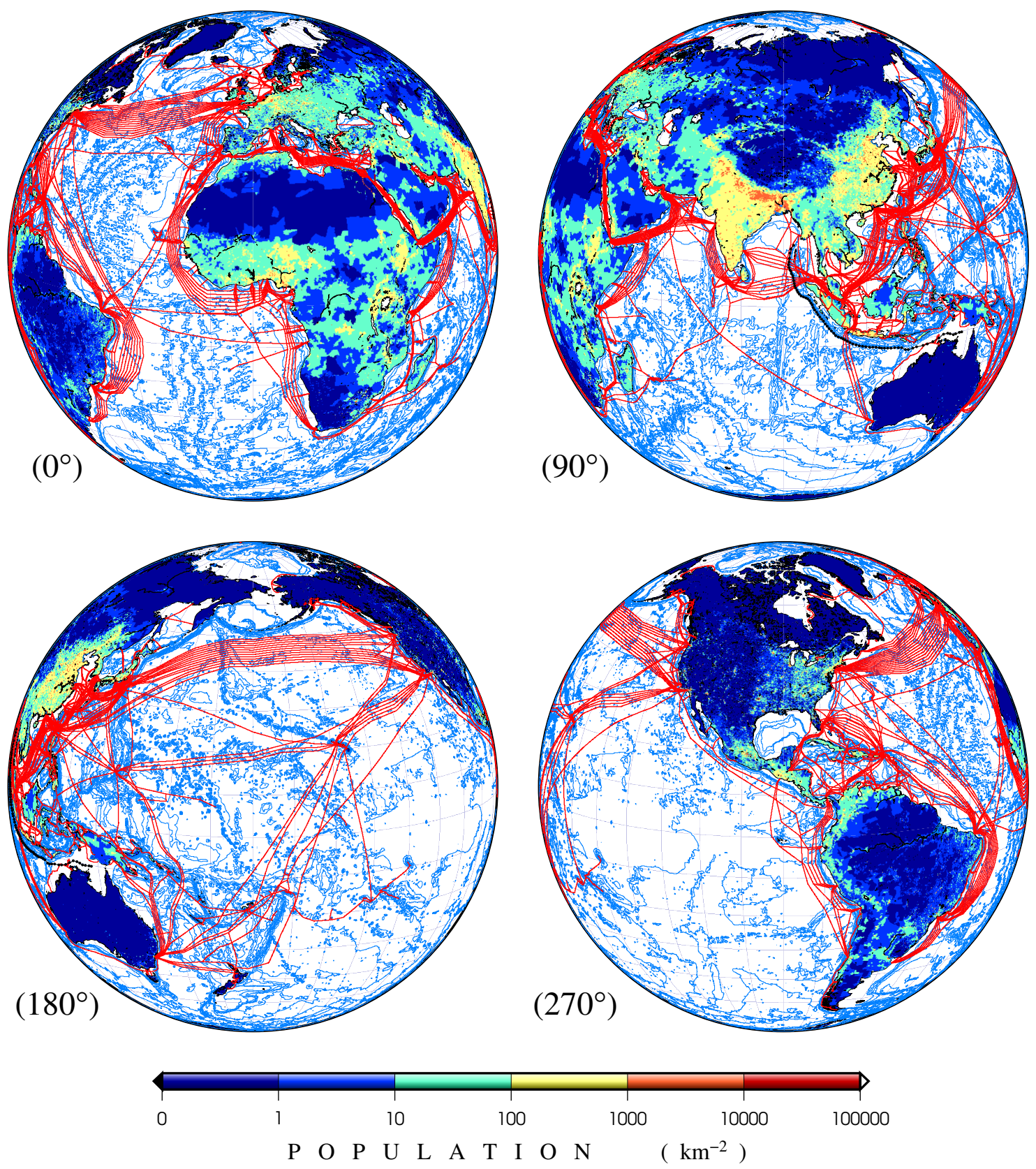

Figure 1: Nominal positions of subsea telecom cables in the world (data obtained from TeleGeography (2020)). Each of the four views show the globe at a given central longitude to provide a complete global visualization. Lands are color-coded according to population density (NASA-SEDAC, 2018). Blue contours show bathymetry. For a full visualization see the animation at https://doi.org/10.7302/0jmy-pa60. The black line shows our proposed SMART array off Sumatra and Java. 
Cables established by the United Nations agencies, International Telecommunications Union (ITU), World Meteorological Organization (WMO), and the UNESCO Intergovernmental Commission (IOC) (Howe et al., 2019). With $>1$ million $\mathrm{km}$ of operational telecommunications cable (refreshed and expanded every 10-20 years) and repeaters every $50-120 \mathrm{~km}$ providing local power and communications, these systems can host sensors (initially ocean bottom temperature, pressure and seismic acceleration) on a global scale at modest incremental cost. The first SMART system is underway funded by Portugal: CAM2 Continent-Azores-Madiera ring, 3700 km, nominally 50 repeaters, to be ready for service in 2024 (Barros, 2019; Matias et al., 2021). A number of other systems are in various stages of consideration, including in the Western Mediterranean, Vanuatu/New Caledonia, French Polynesia New Zealand/Chatham Islands, and India/Oman (Joint Task Force on SMART Cable Systems, personal comm.).

Here we address the benefits of such cable systems offshore of Sumatra-Java for earthquake and tsunami early warning. Our proposed SMART system will serve not just Indonesia but surrounding countries as well, all mutually subject to threats within the entire region.

\subsection{SMART Cables in Indonesia}

Recent disasters in Indonesia call for significant improvements to its multi-hazard early warning infrastructure (Sumatra 2004, IOC, 2009; Mentawai 2010, Lay et al., 2011; Palu 2018, Heidarzadeh et al., 2019; Anak Krakatau 2018, Grilli et al., 2019). Here, in this context, we address megathrust earthquakes and tsunamis, and quantify improved warning times from a SMART submarine cable-based early warning system.

Because of the high societal risk and spatial as well as financial scales of the problem in Indonesia (see Fig. 2), a long-term view - on the order of 10-20 years 
- to a solution is appropriate. The required system must have broad coverage to tackle tectonic-scale events, i.e., earthquakes and tsunamis in both near- and farfields. It is also necessary for such a system to be robust with long life, require little or no in-water maintenance, and be sheltered from the rigors of ocean-surface dynamics and vandalism. These requirements call for an ocean bottom, cable based system. To make this economically feasible, SMART cables must share submarine infrastructure/cost between science and telecommunications. The repeaters in these arrays can host a variety of instruments such as ocean bottom temperature, pressure and seismic sensors at modest incremental cost.

The complete system will be multi-scale with tectonic, regional and local levels of infrastructure. The largest, tectonic scale deals with highest priority Sunda Arc subduction zone that is subject to great, megathrust earthquakes (Fig. 2). The regional scale would specifically address the eastern and northern areas (including the Celebes and Banda Seas and Makassar Strait and Borneo, Sulawesi and Papua) and smaller and more random fault zones. This scale is subject to somewhat lower hazard potential (although as Palu demonstrated, still very much significant). The local scale focuses on specific geohazards of which Anak Krakatau is a perfect example; such cases must be treated both on an individual basis, and in parallel with the larger scales.

In this study, we will focus on the largest scale and leave the other two for future consideration. We note that, for Indonesia, a detailed study is required to consider multiple configurations of systems and scenarios and arrive at an optimal overall design. Any such study must include costing and phasing considerations. This paper is one step in this direction. 


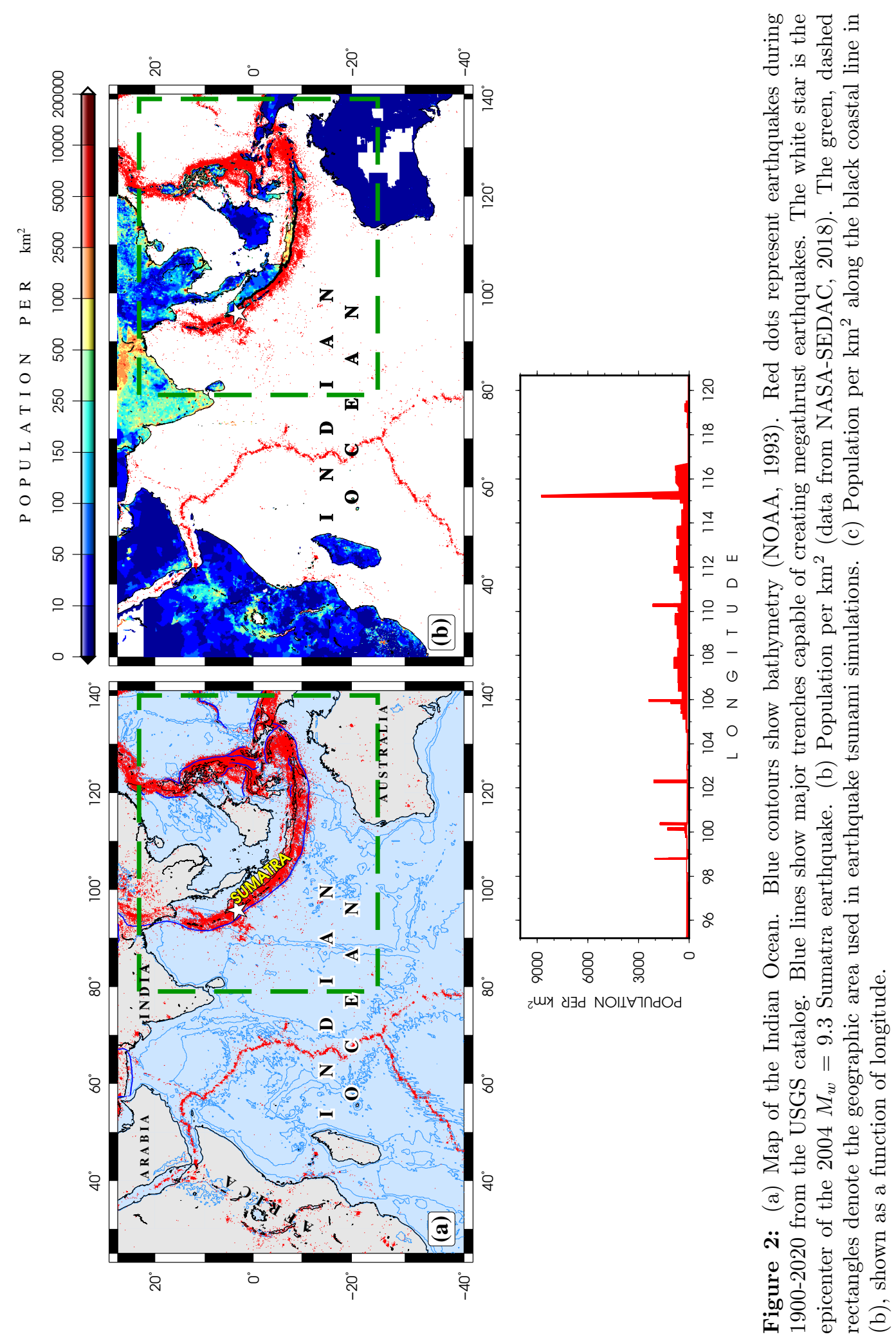




\subsection{Sumatra-Java}

The Sumatra-Java subduction zone is located at the eastern margin of the Indian Ocean (Fig. 2a). The USGS catalog lists about 30,000 earthquakes with magnitudes larger than 3.0 located within $500 \mathrm{~km}$ from the subduction trench. A large number of these events are located within $\sim 3^{\circ}$ from the Sumatran fault, parallel to the trench. They are also caused by many shallow dipping faults in the east (e.g., McCaffrey, 2009). The moderate-to-large size $(\widetilde{M}=4.5)$ along with relatively shallow depth $(\widetilde{H}=35 \mathrm{~km})$ of many such earthquakes pose considerable seismic hazard (e.g., Petersen et al., 2004). Highly populated areas in Indonesia, at times more than 10,000 people per square kilometer (Fig. 2b), imposes significant seismic risk in the region.

Similarly, such earthquakes have resulted in a long history of tsunamis in Sumatra (e.g., Borrero et al., 2006; Monecke et al., 2008). Among these events, the 26 December 2004 tsunami notoriously claimed more than a quarter million lives and displaced more than 1 million people in countries all around the Indian Ocean (IOC, 2009). The source of this tsunami was a $\sim 1300 \mathrm{~km}$ long rupture along the trench (Ammon et al., 2005; Ishii et al., 2005). Complex geometry and the vast areas of excessive slip in the rupture area resulted in a large tsunami with a complicated propagation pattern (Fujii \& Satake, 2007) across the Indian Ocean (Synolakis et al., 2005; Okal et al., 2006b), even reaching as far as Central America, Northern Pacific, and Northern Atlantic Ocean (Titov et al., 2005; Rabinovich et al., 2006).

Eastern Indian Ocean tsunamis have exposed the large population of coastal areas, especially in the near-field, e.g., Sumatra, Java, Thailand, Myanmar, Bangladesh, India and Sri Lanka (Fig. 2c) to high risk of inundation (Kurita et al., 2007; Løvholt et al., 2014; Satake, 2014). Close proximity of the near-field population to the subduction zone has forced the efforts in seismic and tsunami early warning with serious chal- 
lenges (Kanamori, 2006), especially with typical seismic and tsunami arrival times of several seconds and minutes, respectively.

However, the far-field regions such as Pakistan, Oman, Africa (e.g., Kenya, Tanzania, South Africa) and Seychelles are not immune to the tsunami hazard, as was the case with the 2004 event (Okal et al., 2006a; Synolakis \& Kong, 2006; Okal et al., 2009).

\subsection{Earthquake and Tsunami Early Warning in Sumatra}

Currently, earthquake early warning techniques usually aim to provide meaningful, reliable warning within less than $\sim 10 \mathrm{~s}$ after the earthquake origin time (Allen et al., 2020). The offshore location of thrust faults provides some leeway between the onset of earthquake at the epicenter and the arrival of seismic (especially S) waves at coastal areas. However, this also results in tsunami threats. While tsunami waves travel more slowly on the shallow continental slopes and shelves $(\sim 30 \mathrm{~m} / \mathrm{s}$ in $100 \mathrm{~m}$ water depth compared to $200 \mathrm{~m} / \mathrm{s}$ in $4000 \mathrm{~m}$ depth) as they approach land the shoaling process significantly increases their amplitude (Green, 1838). Although slowed down, tsunamis typically arrive at near-field coastlines within $\sim 15$ minutes.

As a result, early detection of seismic and tsunami waves plays a crucial role in the fast evaluation of the hazard and consequently the issuing of necessary warnings to the authorities as well as local communities. A time window corresponding to a tsunami travel time of less than 30-40 minutes from origin to the coastline is often desired in the tsunami early warning process. Estimates of earthquake magnitude and thus rupture size (especially for moderate earthquakes) are usually available within a few minutes after earthquakes (Zollo et al., 2006) and play a crucial role in tsunami early warning in the near-field. Robust evaluation of earthquake ruptures, however, are usually obtained within the first 10 to 15 minutes after the event origin 
time (Angove et al., 2019) through various methods such as moment tensor inversions (CMT solutions; Dziewonski et al., 1981; Ekström et al., 2012); $W$-phase inversion (Duputel et al., 2012) and finite fault models (Ruhl et al., 2017).

After that point, tsunami models use this information to calculate propagation of tsunamis on regional and global scales and provide valid forecast of tsunami arrival times at the vulnerable coastlines. These forecasts are uncertain because the earthquake characterization underlying them has typically only "one-sided" land-based data. While they are routinely evaluated in real-time against data from ocean bottom pressure sensors (OBP) and DART stations, the latter are presently extremely sparse and can only incrementally improve the estimate. More offshore data, seismic and open ocean tsunami wave height, is needed.

There is a reasonable number $(\sim 140)$ of seismic stations close to the trench in Indonesia and Thailand (small triangles in Fig. 3), monitoring the subduction zone and other regional faults. These stations which are maintained by various agencies in several countries, are deployed onland. The data from these stations is mostly available - although perhaps not in real time - via Incorporated Research Institutions for Seismology (IRIS) in various forms (https://service.iris.edu). As seen in Fig. 3, most of the stations are installed on the Sumatra and Java mainlands. This naturally results in an average trench-to-station distance of $\sim 200 \mathrm{~km}$. To our knowledge, there are currently no permanent ocean bottom seismometers deployed in the region (IRIS, 2020).

A few stations are installed on island chains (Siberut, Nias, etc) parallel to the Indonesian main lands, i.e. closer to the trench $(\sim 80 \mathrm{~km})$ as shown by pink triangles in Fig. 3. Also, not all earthquakes occur exactly on the trench, but have hypocenters at some depth within the Benioff zone (Benioff, 1949), resulting in epicenters closer to land. This reduces the travel time of seismic waves to stations and hence would speed 
up detection and consequently the warning process. However, epicenters of shallow $(H<40 \mathrm{~km})$ megathrust earthquakes are typically confined within a narrow band (a few hundred kilometers) from the trench (Schäfer \& Wenzel, 2019). Therefore both seismic and tsunami waves would commence at some distance, and not necessarily close to the shoreline and thus the stations.

Therefore, deployment of seismic and/or tsunami sensors at closer distances to the trench will improve the temporal detection gap, and so we propose the deployment of such instruments in the form of a SMART array on the down-going plate, within a few kilometers of the trench, as depicted by red dots in Fig. 3. The short array-to-trench distance removes the complexities in resolving the source mechanism which would otherwise exist when using far-field tsunami waves: various possible combinations of fault dimensions can result in similar source solutions due to the decay in tsunami amplitude over distance (Carrier, 1991). Such a large span of underwater cable $(\sim 8,000 \mathrm{~km})$ is likely to be installed incrementally over time. The cable would be just offshore and seaward of the trench on smooth and level bottom where cabledamaging submarine landslides are less likely to occur relative to the landward slopes. Similarly, the trench would prevent any turbidity flows from reaching the cable. Also, this avoids the risk of bottom fishing trawling and ship anchoring. We note that such flat deployment sites result in simpler records as slope often complicate both elastic and hydrodynamic measurements and make them difficult to unravel, especially in real time (Hilmo \& Wilcock, 2020).

The proposed SMART array in Fig. 3 starts just west of the Andaman Islands (station \#1) in the north and ends in the Arafura Sea, northern Australia in the south (station \#76), covering (and parallel to) the entire Andaman-Sumatra-Java trench system. Geographic coordinates of the proposed array are available at https://doi. org/10.7302/0jmy-pa60. We note that the proposed array can play a crucial role in 
the detection of small-scale tsunamis in the Lombok Island region, similar to the 2018 series (Tsimopoulou et al., 2020). The proposed extension of the array eastward into the Timor Sea is intended to monitor the progress of Sumatra-Java tsunamis onto northern Australia. This is also done in anticipation of possible future events in the Banda Sea, such as the $M_{w}=8.6$ earthquake of 01 Feb 1938 (Okal \& Reymond, 2003; Burbidge et al., 2008). The parallel geometry of the array also provides the opportunity of sampling earthquake tsunamis at various azimuths. A perpendicular array would only record such tsunamis at a single direction, hence lacking the necessary coverage to uniquely resolve a focal solution for the earthquake.

SMART station spacings are ideally $35 \mathrm{~km}$ in deep water based on theoretical arguments for resolving tsunami wave elevation and direction (Nosov, 2016), but this may be relaxed to $\sim 70-120 \mathrm{~km}$, more typical of telecom repeater spacing for these length cables. In this study, spacing varies between 50 and $200 \mathrm{~km}$. This geometry recognizes the ambiguity of recorded signals from large numbers of interior shelf and slope nodes (Hilmo \& Wilcock, 2020) as well as the economic infeasibility of such a task as in the Japanese dedicated early warning systems S-net, DONET, and N-net (Aoi et al., 2020).

The proposed array may be at a finer spatial resolution than logistically possible and what is prescribed. However, in this study, we endeavor to explore the potential of SMART cables in earthquake and tsunami warning. Obviously, any future deployment of such a network can be achieved through decimating our proposed array within reason. The otherwise dense network (average spacing of $\sim 80 \mathrm{~km}$ ) turns into a coarser array (average $\sim 100 \mathrm{~km}$ ) in the southeast due to the significantly lower seismicity of the region as well as the large areas with shallow bathymetry in the Timor and Arafura sea - median depth of $\sim 70$ m altogether (ETOPO1: Amante \& Eakins, 2009). The latter results in fast dissipation of tsunami energy as the tsunami travels 

244 study.

slowly through the shallow water.

In the following sections we will investigate the performance of the proposed SMART array in tsunami and earthquake detection. We will consider tsunamis from both tectonic and landslide sources. While the latter are more localized compared to their tectonic counterparts, their potentially large amplitudes and extremely nonlinear triggering processes (seismic, atmospheric, etc), warrants special attention in any such 


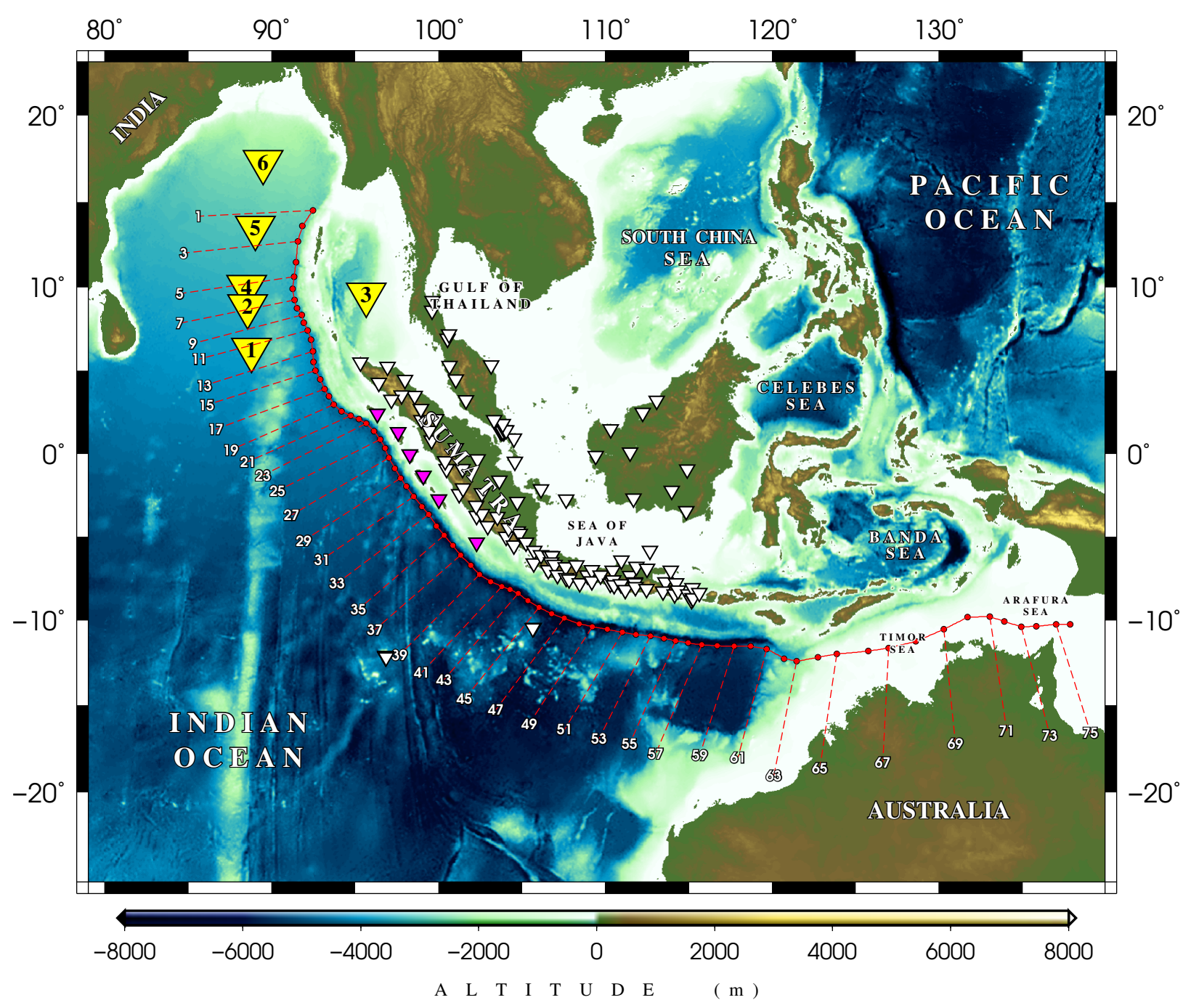

Figure 3: Proposed SMART array (red dots) off the Sumatra trench. The 76 SMART repeater stations are indexed from north to south. DART stations are shown as yellow inverted triangles and are indexed from south to north. Note that the majority of these DART stations are not currently operational. Smaller, white triangles represent seismic stations. Pink triangles are island seismic stations which are closer to the trench.

\section{Method}

\section{$2.1 \quad$ Tsunami Simulations}

The initial conditions of our simulation of earthquake tsunamis are ocean bottom deformations calculated from hypothetical static double-couple sources using Mansinha \& Smylie's (1971) algorithm. This algorithm computes surface deforma- 
tions from a uniform slip field on a buried inclined fault in a half-space. The choice of static over kinematic sources was made due to the small effect of rupture kinematics in the near-field (Williamson et al., 2019; Salaree et al., 2021).

We then use the Method of Splitting Tsunamis (MOST) (Titov et al., 2016) to simulates the tsunamis in the Indian Ocean. MOST solves the full, nonlinear shallow water approximation of the Navier-Stokes equations and has been extensively validated through laboratory and field studies, following standard international protocols (Synolakis, 2003; Synolakis et al., 2008).

We simulate earthquake and landslide tsunamis in the ETOPO2 bathymetry grid (Amante \& Eakins, 2009) and an interpolated version of it down to 35 arcseconds, respectively. This is to be sure the wavelength sufficiency conditions (e.g., as prescribed by Shuto et al. (1986)) were satisfied. Simulations are carried out in 12hr time windows for earthquakes using time steps of $\delta t=5 \mathrm{~s}$. For landslide scenarios we used smaller time windows of $4 \mathrm{hr}$ using time steps of $\delta t=2 \mathrm{~s}$. The time steps were selected to satisfy the CFL conditions (Courant et al., 1928). Due to our interest in studying the offshore behavior of tsunamis and in the absence of detailed coastal bathymetry maps, we stop the calculation at a depth of $20 \mathrm{~m}$, close to the shoreline. As such, no run-up values are calculated.

\subsection{Earthquake Arrival Times}

We use the TauP toolkit (Crotwell et al., 1999) to calculate seismic phase travel times from earthquake hypocenters to stations. TauP applies Buland \& Chapman's (1983) method to computing phase travel times using spherically symmetric velocity models and arbitrary phases. In this context, we use PREM (Dziewonski \& Anderson, 1981) as the velocity model due to its simplicity.

We note that upon very small epicentral distances lower-case phases ( $\mathrm{p}$ and $\mathrm{s}$ ) 
and their upper-case counterparts $(\mathrm{P}$ and $\mathrm{S})$ can be used interchangeably, as long as no reflections are considered. Thus, from here onward we will use the general terms Pand S-waves to identify direct arrivals of compressional and shear waves, respectively, in order to avoid confusion.

\subsection{Submarine Landslides}

Submarine landslides follow the direction of steepest descent of the bathymetry field (e.g. Salaree \& Okal, 2015) and typically occur at slopes between $\sim 3 \%$ and $\sim 6 \%$, but can also take place at slopes as low as $\sim 1 \%$ in very shallow waters (e.g. Skempton, 1953; Prior et al., 1982). We calculate a field of slope for the simulation area as the gradient of the bathymetry grid. We then pinpoint the areas matching the slope criterion (i.e., gradient modulus between 1-6\%) and design slides to match the azimuth of the gradient vector.

Following the formalism of Synolakis et al. (2002), we design the submarine slides as simultaneous hydrodynamic dipoles with positive (hump) and negative (trough) initial surface elevations. We use $\eta_{ \pm}, \alpha_{ \pm}$and $\gamma_{ \pm}$as geometrical dimensions of slide dipoles, i.e., height/depth, along slide dipole length, and normal to dipole length. Plus and minus signs in these parameters denote hump and trough, respectively (Okal \& Synolakis, 2004; Salaree \& Okal, 2015).

\subsection{Tsunami Arrival Residual}

To investigate the contribution of SMART stations to early detection of tsunami waves from the given rupture scenarios, we construct 2-D matrices comparing the arrival times of tsunamis at SMART stations to those of the DART array. The elements in such a matrix are the difference in tsunami arrival time for each pair of SMART and DART stations, as given by the residual time, $\mathbf{R}$ in Eq. (1) 


$$
R_{i j}=S_{i}-D_{j}
$$

where $S_{i}$ and $D_{j}$ are tsunami arrival times at the $i$-th SMART station $(1<i<76)$ and the $j$-th DART buoy $(1<j<6)$. We also define the scalar quantity, $\Lambda$ as the sum of all the elements in $\mathbf{R}$,

$$
\Lambda=\sum_{j=1}^{6} \sum_{i=1}^{76} R_{i j}
$$

where negative values of $\Lambda$ would correspond to an overall good contribution of SMART cables and vice versa. We note that each instrument has a different frequency and pressure response and SMART cables are significantly (e.g., Mofjeld et al., 2001). However, for consistency as well as for practical purposes, here we assume a common detection threshold of $2 \mathrm{~cm}$ following Meinig et al. (2005).

\section{Tsunamis}

The 2004 Sumatra-Andaman earthquake ruptured the northern segments of the subduction zone as shown in Fig. 4. The rupture propagated at a speed of $\sim 2.5$ $\mathrm{km} / \mathrm{s}$ toward the north northwest with a duration of at least $\sim 500 \mathrm{~s}$ (Ammon et al., 2005; Lay et al., 2005; Ni et al., 2005).

In the wake of the human tragedy due to the following tsunami, six DART stations were deployed by India and Thailand at some distance from the rupture area for future tsunami warning. A simple ray-tracing experiment, however, shows that the tsunami waves from rupture epicenter would have taken at least 45 minutes to arrive at the first DART buoy (\#1 in Fig. 4). Considering the significantly faster typical speed of earthquake ruptures compared to tsunamis $(\sim 12 \times)$, as well as the 
parallel geometry of the DART network relative to the trench, it would have taken roughly the same amount of time for the tsunami to arrive at the rest of stations.

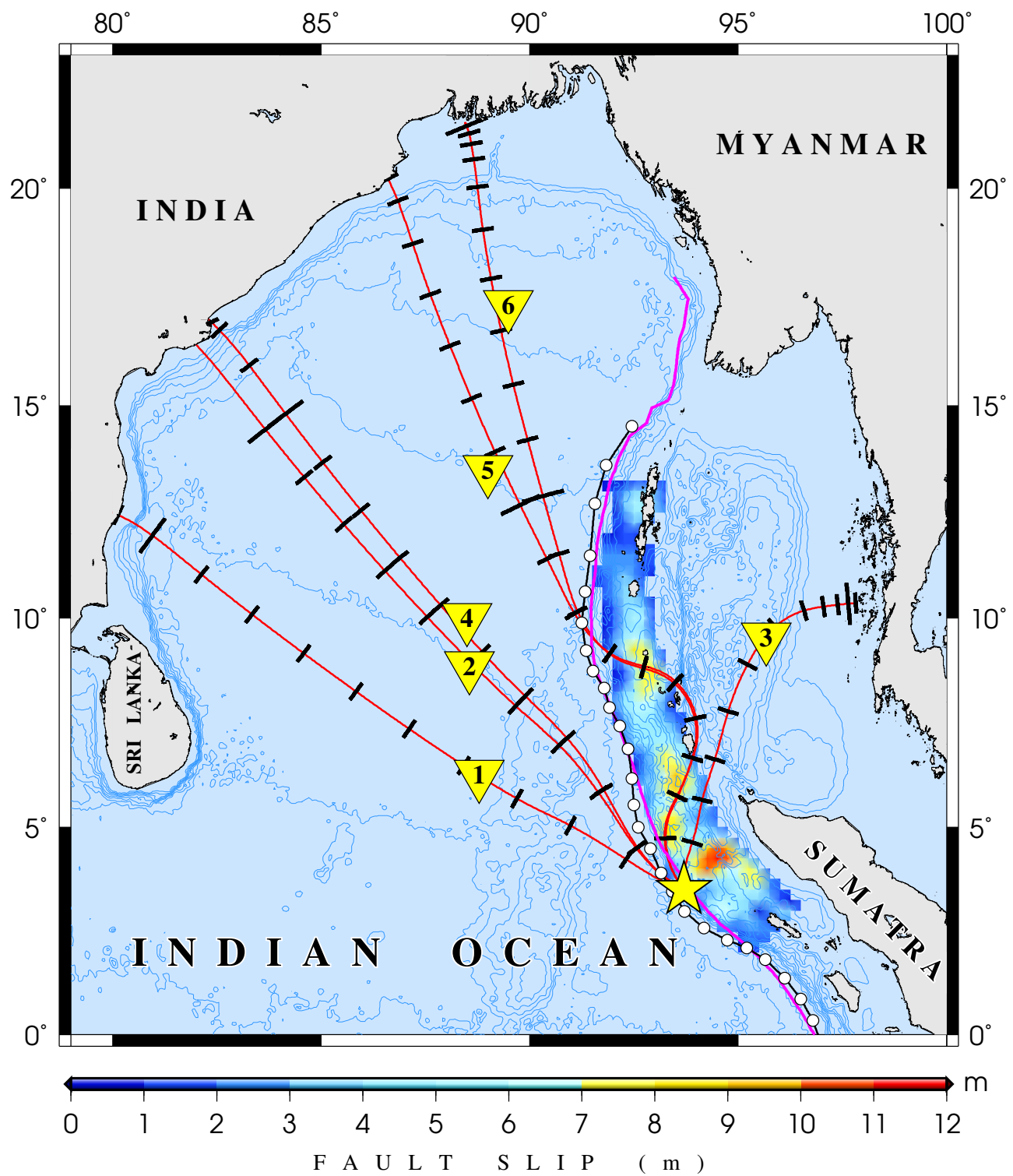

Figure 4: Ray-tracing of the 2004 tsunami from the yellow star taken as the up-dip section of largest slip patch. Six rays (red) passing through DART stations (yellow triangles) are shown. Finite fault solution (Ammon et al., 2005) is shown in color. Black tick marks are added every 15 minutes along the ray paths. The pink line shows the Sumatra-Andaman trench. The white circles are SMART stations placed right off the trench. Blue contours represent bathymetry.

Thus, and as discussed in section 1.2, we will focus our efforts on near-field 
simulation of tsunamis on a linear array of SMART stations parallel and very close to the trench.

\subsection{Rupture Scenarios}

The most well-constrained earthquake rupture in Sumatra and Andaman is the $M_{w}=9.3$ event in 2004. Several other historical ruptures such as the great earthquakes of 1797 and 1833, respectively in Padang and Bengkulu (Borrero et al., 2006), and 2010 Mentawai (Hill et al., 2012) have also been subject of extensive studies.

In this study, we consider some of the worst-case earthquake/tsunami scenarios in the region which could rise due to various forms of seismic gaps. We adopt five earthquake rupture scenarios in Sumatra following Salaree \& Okal's (2020) work and models I-V are identical to their models S-I to S-V. Model I is a rendition of the 2004 event, and model II is similar to Okal \& Synolakis' (2008) model of the 1833 earthquake. Model III represents the main 2007 Bengkulu earthquake, using the simple model by Borrero et al. (2009). Model IV is set up to release the strain leftover on the 1797 and 1833 ruptures after the 2007 Bengkulu event, as the widely anticipated Padang earthquake (McCloskey et al., 2010). Similar to model IV, model V is expected to close the Padang seismic gap, but also extends south towards the Sunda Strait.

Future ruptures in Java are poorly constrained. United States National Oceanic and Atmospheric Administration (NOAA) and the Agency for Meteorology, Climatology and Geophysics of Indonesia (BMKG) list respectively about 90 and 70 tsunami sources east and north of Java island and Nusa Tenggara (Fig. 5; Hamzah et al., 2000). Such tsunamis are often hosted by northern fault systems such as the back-arc Flores thrust zone in Bali Sea and Flores Sea (Anugrah \& Sunardi, 2012; Yang et al., 2020) contrary to what would otherwise be expected from the dominant Sumatra-Java 
subduction. For instance, the aforementioned fault created the $M_{w}=7.8$ earthquake and the following tsunami on 12 December 1992 resulting in hundreds of casualties and significant damage (Yeh et al., 1993).

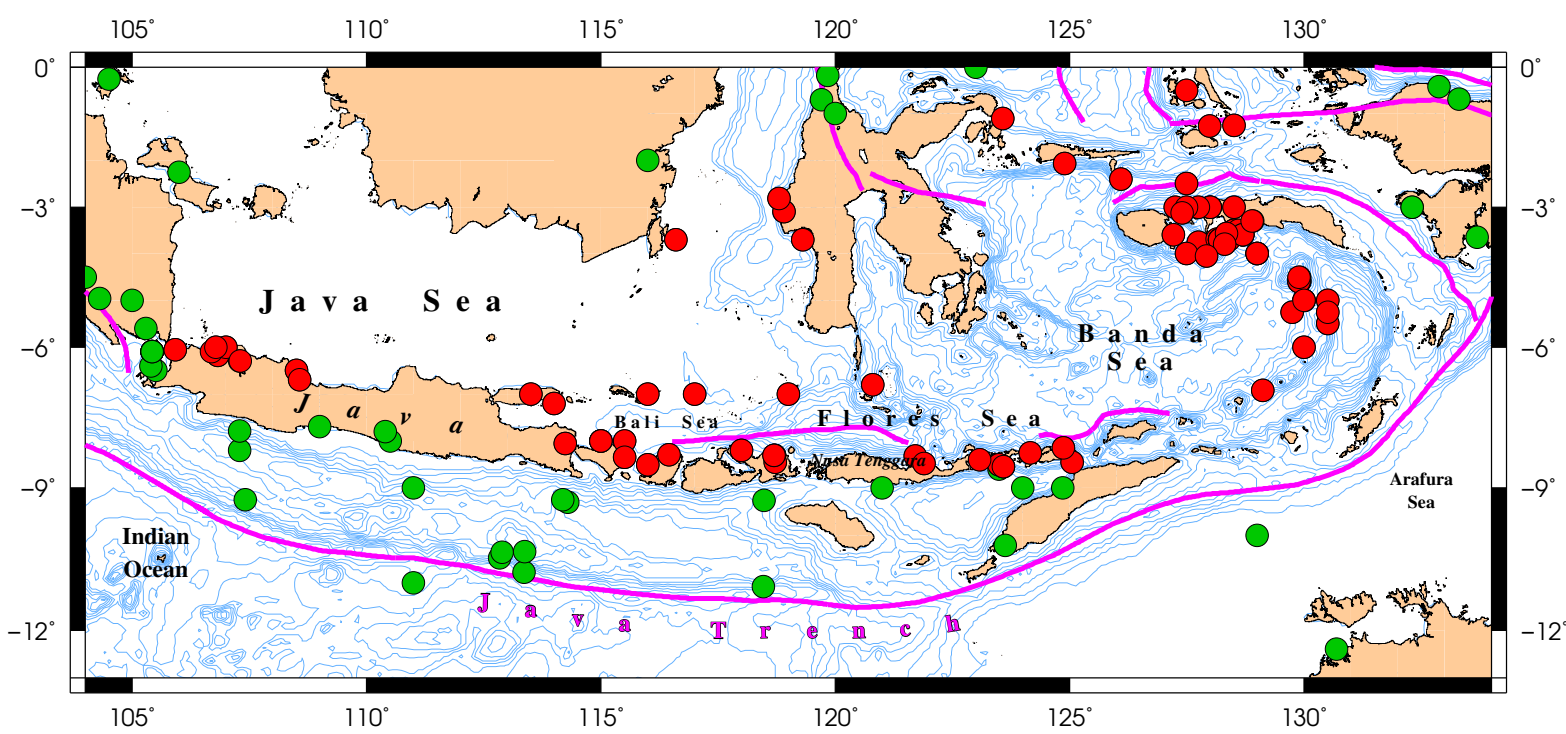

Figure 5: Tsunami sources in the Java region (NGDC/World Data Service, 2021) show by dots representing fore-arc (green) and back-arc (red) events. Blue contours and pink lines show bathymetry and fault zones, respectively.

Previous studies such as Horspool et al. (2014) and Setiyono et al. (2017) have investigated the tsunami hazard in fore-arc Java using a large number of pre-computed inundation scenarios from hypothetical sources. However, to obtain a more physically sound scenario, we use a single large rupture $\left(M_{w} \sim 9\right)$, model VI, as a worst-case scenario by designing a composite source similar to Scenario 3 in Widiyantoro et al. (2020). Fields of static vertical deformation for these rupture models are shown in Fig. 6. Table 1 lists source dimensions along with maximum tsunami amplitudes and detecting stations (see section 3.3.1). 

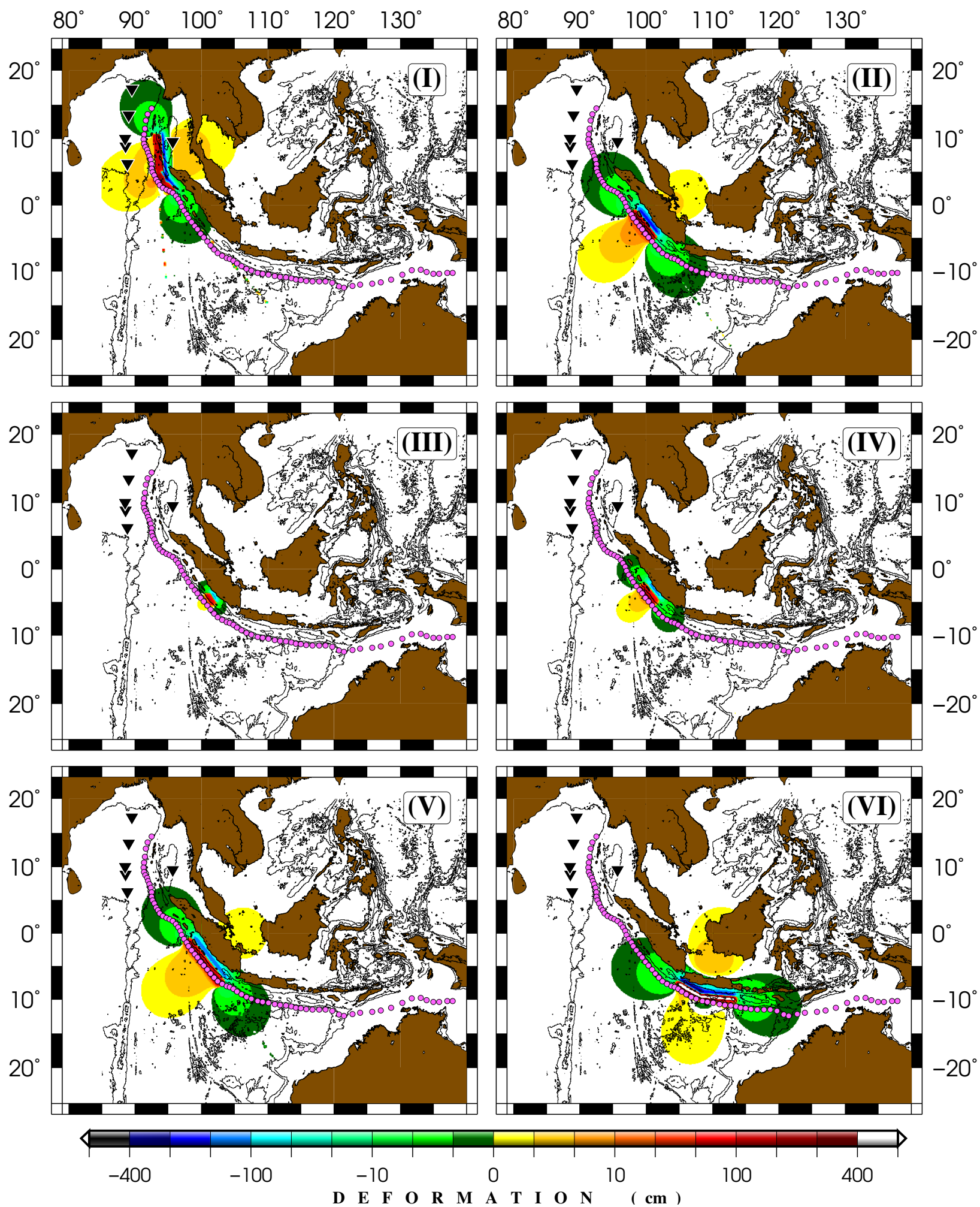

Figure 6: Fields of static vertical deformation for models I-VI are calculated using the algorithm of Mansinha \& Smylie (1971). Black triangles and pink dots show DART and SMART stations, respectively. Black contours are bathymetry. 
Table 1: Source parameters for the six rupture scenarios. Note the composite nature of models I and VI each of which are made up of two smaller segments. The $6^{\text {th }}$ and $7^{\text {th }}$ columns list maximum tsunami amplitudes across the simulation grid, and the number of "recording" stations within five minutes after the origin time for each scenario.

\begin{tabular}{|c|c|c|c|c|c|c|c|c|}
\hline $\begin{array}{l}\text { Source } \\
\text { Model }\end{array}$ & \multicolumn{2}{|c|}{$\begin{array}{c}\text { Centroid } \\
\text { Coordinates }\end{array}$} & \multicolumn{3}{|c|}{$\begin{array}{c}\text { Rupture } \\
\text { Dimensions }\end{array}$} & $M_{0}$ & $\begin{array}{c}\text { Max. Tsunami } \\
\text { Amplitude }\end{array}$ & $\begin{aligned} & \text { Stations } \\
< & 5 \text { Minutes }\end{aligned}$ \\
\hline- & Lon. & Lat. & $\mathbf{L}(\mathrm{km})$ & W (km) & $d(m)$ & $\times 10^{28}$ dyn-cm & $\eta(\mathbf{m})$ & - \\
\hline $\mathbf{I}$ & & & & & & 105 & & \\
\hline I.a & 94.6 & 3.3 & 382 & 150 & 11.5 & 32 & & \\
\hline I.b & 93.8 & 7.0 & 818 & 150 & 12.4 & 73 & 11.5 & 25 \\
\hline II & 99.7 & -3.0 & 550 & 175 & 13.0 & 62 & 7.3 & 27 \\
\hline III & 101.6 & -4.4 & 190 & 95 & 5.6 & 5 & 3.3 & 3 \\
\hline IV & 100.6 & -3.7 & 350 & 175 & 6.0 & 18 & 3.7 & 12 \\
\hline $\mathbf{V}$ & 100.7 & -4.25 & 900 & 175 & 8.0 & 62 & 5.6 & 28 \\
\hline VI & & & & & & 65 & & \\
\hline VI.a & 106.5 & -8.30 & 400 & 80 & 20.0 & 33 & 147 & 27 \\
\hline VI.b & 110.65 & -9.5 & 600 & 80 & 15.0 & 32 & 14.7 & 27 \\
\hline
\end{tabular}

While models I-VI do not fully cover all the seismic potency of the entire Andaman-Sumatra-Java trench system, they provide an adequate coverage of the subduction zone along the strike of trench. Similarly, these models span a wide range of moment magnitude and thus they offer a reasonable measure of the tsunami hazard in the eastern Indian Ocean. In Java, our choice of a single, worst-case model in Java is justified by the more or less uniform coastal morphology, bathymetry and trench-to-coast distance along longitude. Such a setting provides a self-similar hydrodynamic problem along longitude, and therefore, the large composite source is a feasible mechanism representing the local tsunami arrival times from other possible sources.

Maximum tsunami amplitudes across the eastern Indian Ocean from these six models are shown in Fig. 7. Our proposed SMART array and coastal tsunami 
amplitudes along Sumatra and Java are also shown in Fig. 7 with pink dots and bars, respectively. As expected, the more complex sources in model I (i.e., the 2004 Sumatra) and model VI (worst-case Java scenario) create more complex propagation patterns. They also result in larger coastal amplitudes due to large patches of rupture slip. However, models II and V seem to be more focused in the far-field due to their more homogeneous, long ruptures (Carrier, 1991). Besides, as expected, narrower directivity lobes of longer ruptures would result in more focused bundles of energy in the far-field (Ben-Menahem \& Rosenman, 1972). Models III and IV produce smaller tsunamis due to smaller ruptures (Salaree \& Okal, 2020). 


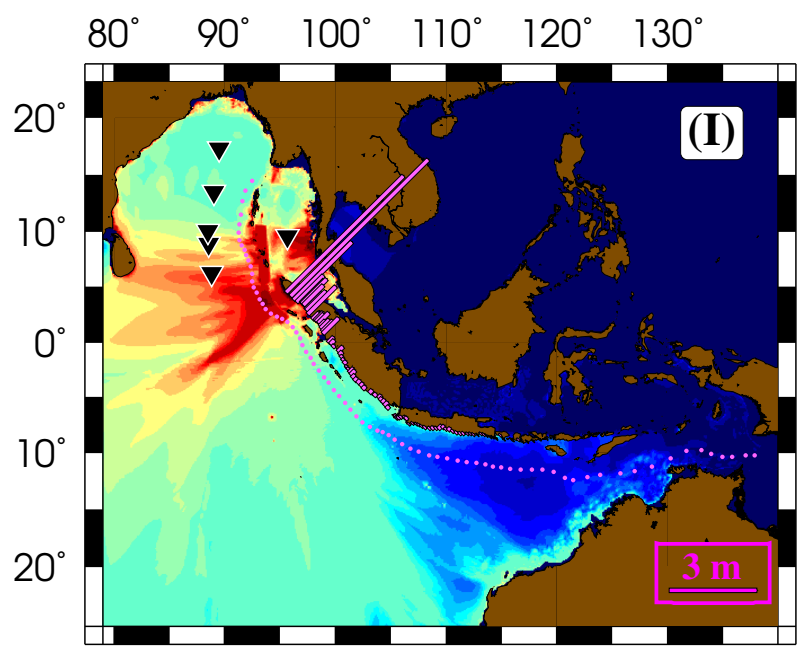

$80^{\circ} \quad 90^{\circ} \quad 100^{\circ} \quad 110^{\circ} 120^{\circ} 130^{\circ}$
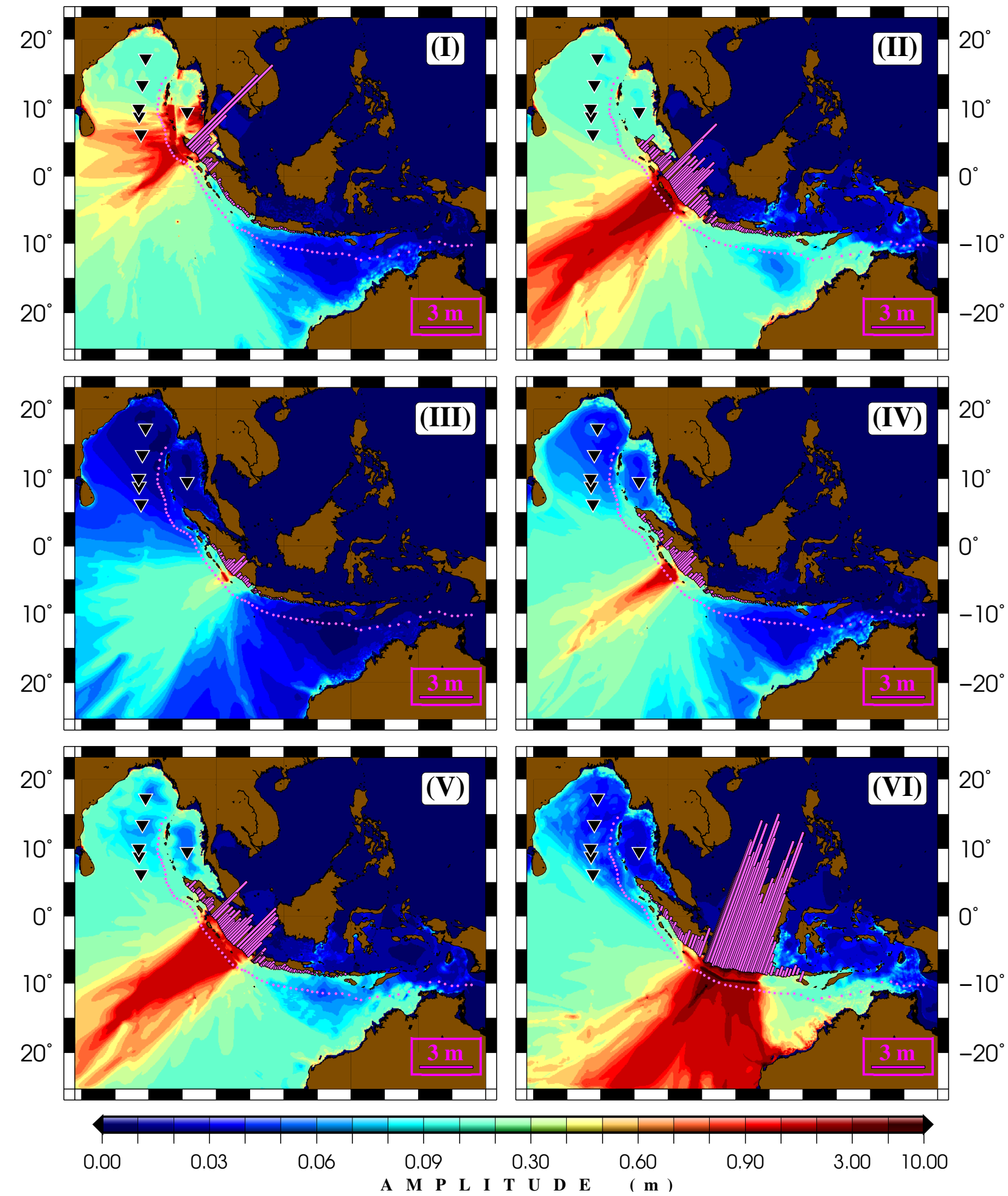

Figure 7: Tsunami simulations of rupture scenarios in Sumatra (I-V) and Java (VI). Pink bars represent coastal tsunami amplitudes (at $20 \mathrm{~m}$ water depth). Panels are labeled according to their respective model index. SMART and DART stations are shown as pink dots and black triangles, respectively. 


\subsection{Tsunamis from Submarine Landslides}

Submarine landslides are significant and usually ignored sources of tsunami hazard (e.g., Ward, 2001; Harbitz et al., 2014; Salaree, 2019). The scientific community's awareness of the importance of landslides in the generation of tsunamis was truly awakened during the Papua New Guinea event of 17 July 1998 which resulted in more than 2200 deaths, and for which Synolakis et al. (2002) proposed generation by a landslide, and was later documented in the local bathymetry by Sweet \& Silver (2003). The recent Palu and Anak Krakatau (Muhari et al., 2018; Grilli et al., 2019) events have catalyzed renewed attention to the general topic of landslide tsunamis.

From the three necessary ingredients of submarine landslides, i.e., loose sediments, slopes and triggering mechanism, there is an abundance of the latter two in the Sumatra region.

Sumatra and Java are seismic (see section 1.2). The USGS Repository of Earthquake-Triggered Ground-Failure lists seven earthquakes in Java and Sumatra with reported landslides since 1982. The cumulative field of peak ground acceleration (PGA) of shallow $(H<40 \mathrm{~km})$ earthquakes from the 1,887 events in the CMT catalog (Ekström et al., 2012) computed using the algorithm by Campbell \& Bozorgnia (2003) and smoothed to accommodate fault finiteness shows considerable amount of cumulative offshore shaking (Fig. 8a). Given enough time, such large amounts exceeding 30\%-g (ignoring the areas in red, i.e., shaking from the 2004 CMT centroid), can contribute to the highly nonlinear triggering process of landslides by large enough, future earthquakes. Permana \& Singh (2016) investigated similar scenarios in seismic sections from northeastern margins of the Mentawai Island.

The region also contains large offshore areas with $2-6 \%$ slopes, i.e., capable of hosting submarine slides, as shown in Fig. 9a. Nevertheless, most of the offshore sediment in Sumatra is derived from the oceanic plate, accumulating in the form of 
an accretionary wedge with only a small amount entering the system from the land areas (Tappin et al., 2007). Notwithstanding the deficiency in sediment budget, we note that the excessive tsunami amplitudes of the 2004 event may have been due to either secondary tectonic sources such as splay faulting (Plafker, 2007) or coseismic triggering of submarine landslides. In the south, however, Java Trench exhibits features of tectonic erosion (Kopp et al., 2006) which could explain the history of large slides (Brune et al., 2010).

Hence, we also consider tsunamis from submarine landslides in the area of study using the methods discussed in section 2.3, bearing in mind the unbalanced probability of such events in Java and Sumatra. Using the discussed criteria, we select 58 slide scenarios with sizes and azimuths determined from modulus and azimuth of the gradient field as shown in Fig. 9a and 9b. In these figures, black and yellow arrows show the positions and orientations of the designed dipoles. Sizes of the plotted arrows are proportional, and not equal to the length of dipoles. The larger number of tsunami simulations from landslides compared to earthquakes is to compensate for the fewer constraints on the location and extent of such events.

We set the geometric parameters of the hydrodynamic dipoles to $\eta_{-}=20 \mathrm{~m}$, $\eta_{+}=10 \mathrm{~m}, \alpha_{-}=0.1, \alpha_{+}=0.06, \gamma_{-}=0.7, \gamma_{+}=0.54$ for all slide scenarios (see section 2.3). While this uniform approach will bias the calculated coastal amplitudes, it is acceptable as we simply seek to obtain estimates of potential tsunami amplitudes. Then we simulate the tsunamis from the prepared slides. A cumulative field of maximum tsunami amplitude from these scenarios are shown in Fig. 8b. Yellow and pink bars represent the relative tsunami amplitudes at SMART stations, and close to shoreline (average depth of $\sim 62 \mathrm{~m}$ ), respectively. 


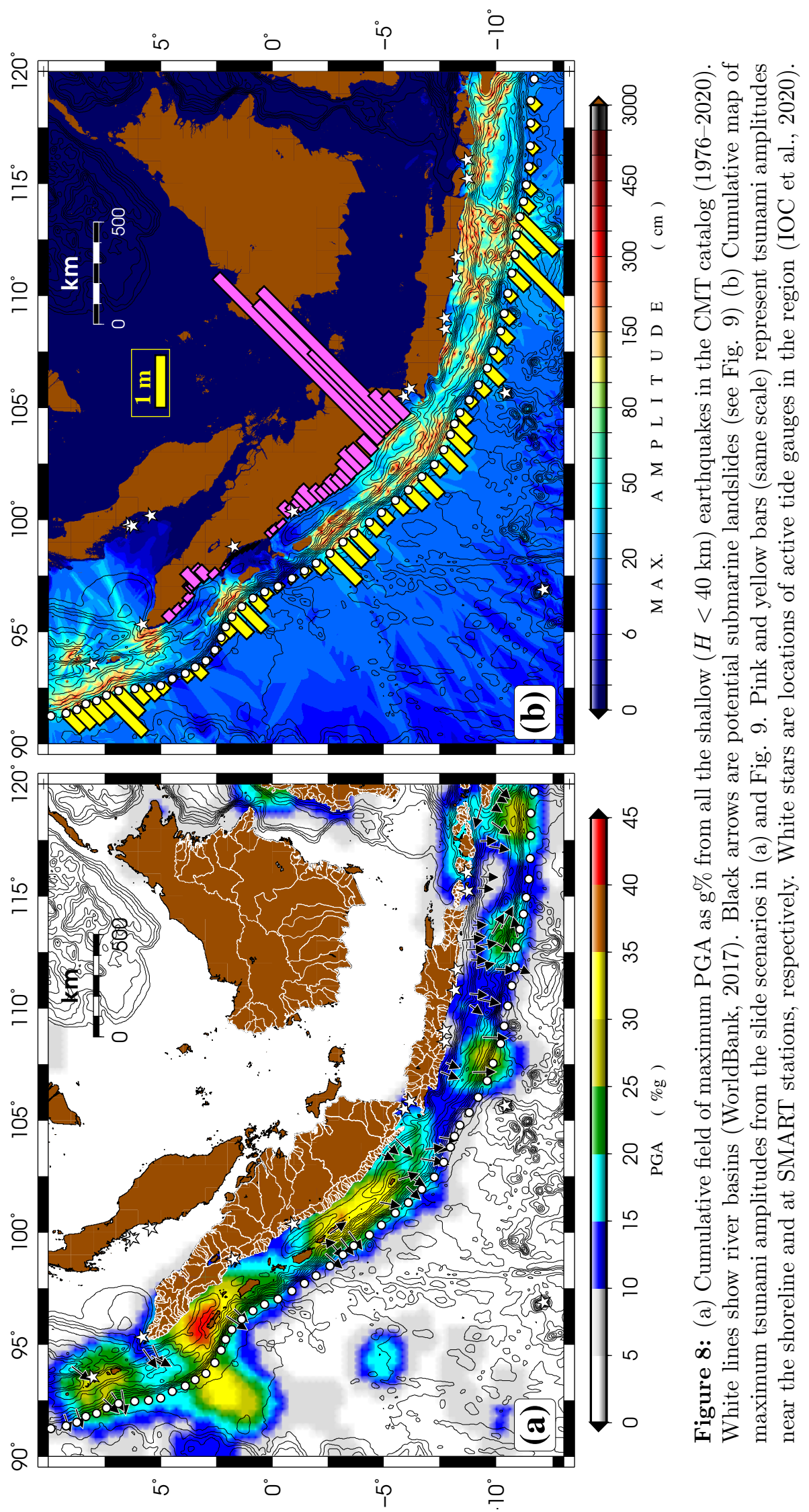




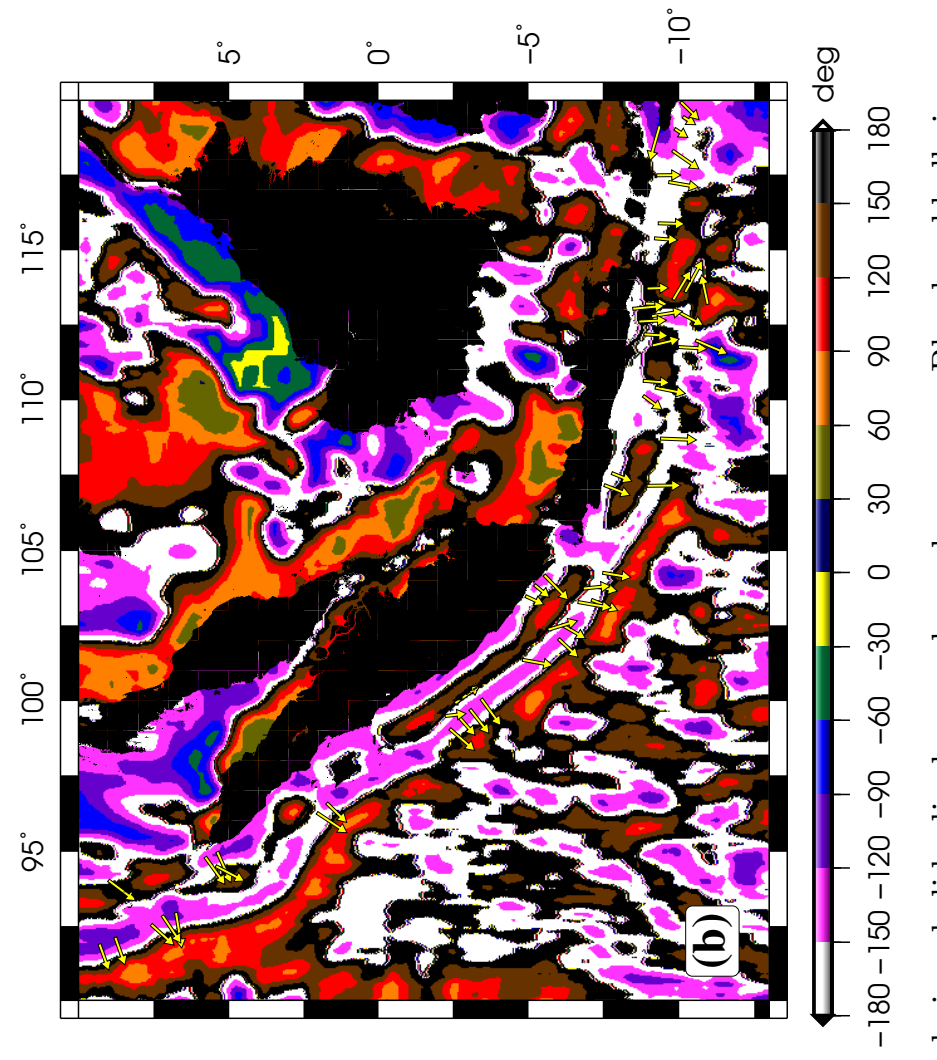

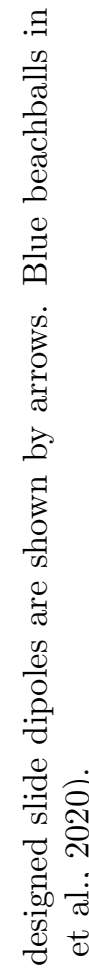

总节

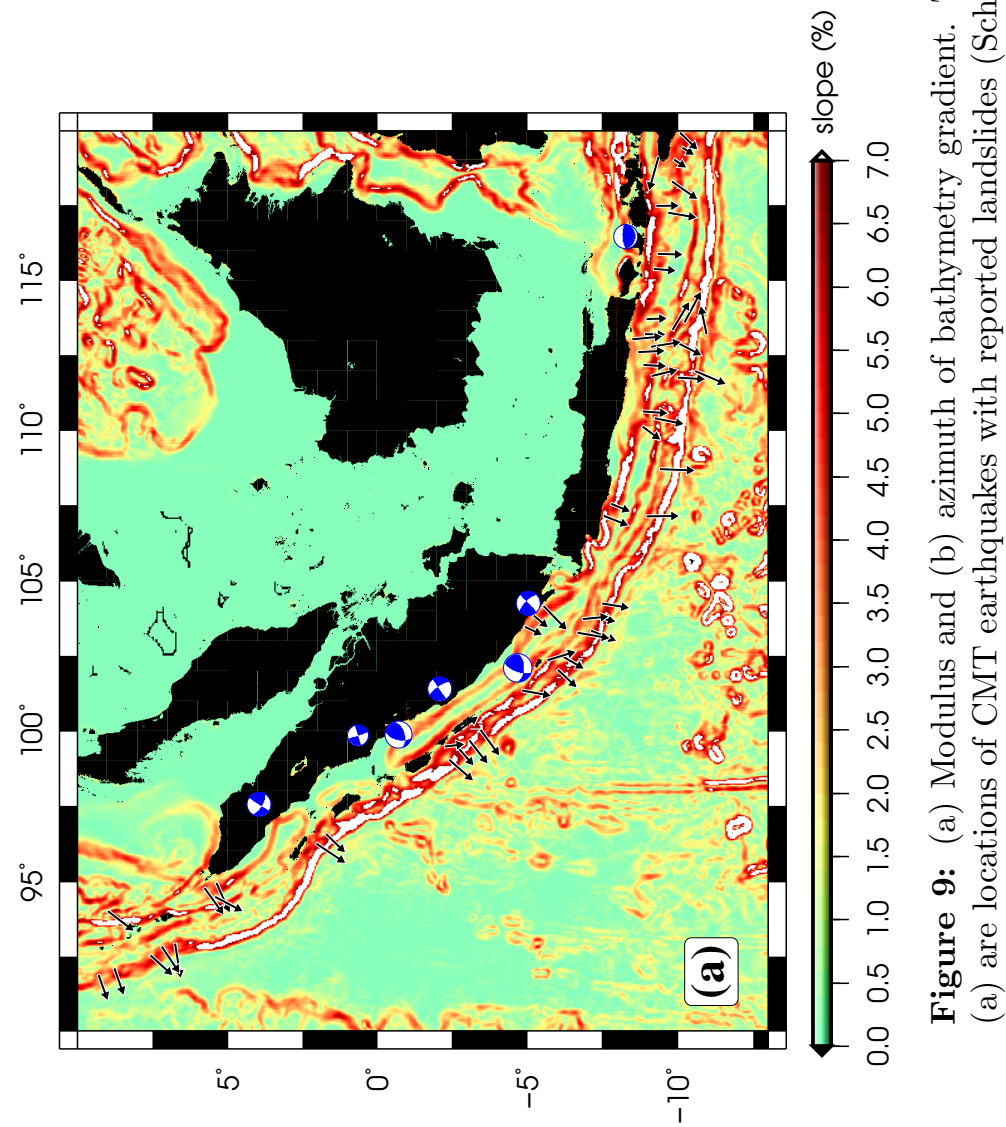




\subsection{Tsunami Detection by the SMART Array}

\subsubsection{Earthquake Tsunamis}

Visual representations of calculated $\mathbf{R}$ matrices (section 2.4) for our six rupture scenarios are shown in Fig. 10. The cells across each panel in Fig. 10 are color-coded according the value of corresponding elements, i.e., residual time in seconds. In Fig. 10, warmer colors (black to yellow) correspond to negative values in the matrix, meaning earlier arrivals at SMART stations relative to their DART counterparts $\left(t_{\text {SMART }}<t_{\text {DART }}\right)$. In model $\mathrm{I}$, the majority of SMART stations receive tsunami signals significantly earlier than DART buoys, with the exception of DART station \#3. The latter is slightly closer to the deformation maximum and receives the tsunami signal less than 10 minutes earlier than the SMART array. We note that in the Okada solutions of continuous ruptures, the deformation area extends to well beyond the main rupture (Steketee, 1958) and as such, stations (both SMART and DART) in the coseismic deformation field, detect the tsunami signal earlier (Fig. 6). Also, due to the thrust geometry of model I, the down-dip direction would experience larger deformation. These factors explain why DART station \#3 is detecting the tsunami slightly earlier than the otherwise closer SMART stations. The advantage of SMART cable deployment in such a scenario with comparable tsunami arrival times is the recording of tsunami signals on a large number of SMART stations whereas in the case of single DART station there is a significant uncertainty margin.

In models II-VI, SMART stations detect the tsunami significantly earlier than the DART network, as evident in the large, negative values of $\Lambda$. The deceptively non-negative value of $\Lambda(\Lambda=0)$ for model III is due to the fact that a large number of SMART stations never receive the tsunami signal, and are assigned the maximum $S_{i}$ value by the end of simulation. Wider directivity lobe of the rupture in model III combined with geometrical spreading results in a widespread moderate coastal 


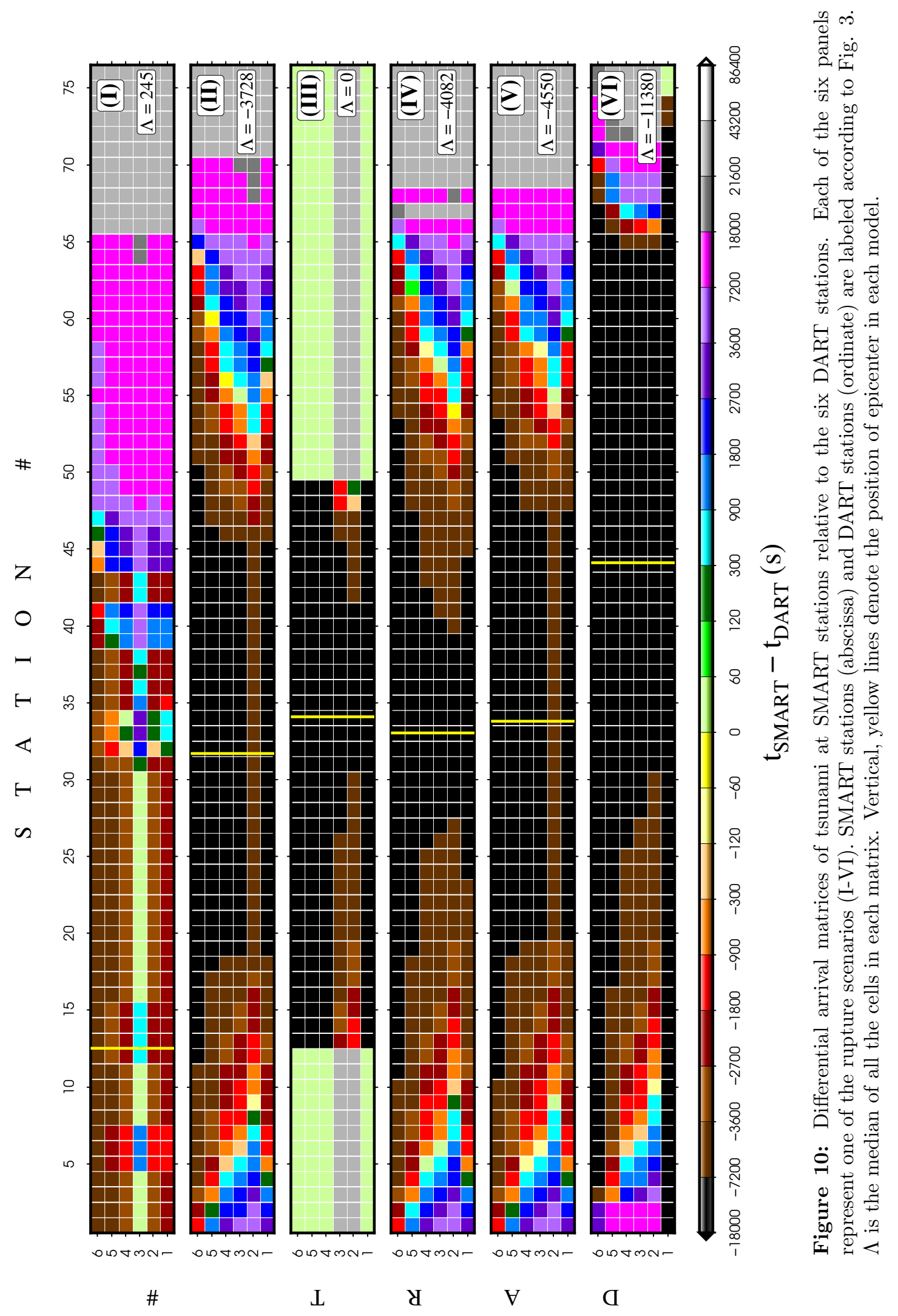


amplitude which is not focused enough in the far-field to be detected by DART buoys (detection threshold of $2 \mathrm{~cm}$ ).

While SMART stations detect tsunamis significantly earlier than the current DART stations, they also provide an increasingly more complete picture of the tsunami source and propagation of the tsunami over time. Fig. 11 shows the cumulative number of detecting SMART stations over simulation time. As we can see in Fig. 11, on average, 20 SMART stations will record the tsunami within a minute after the onset of ruptures. Even for the obvious outlier, model III, the tsunami will be sampled by at least two stations.

The number of detecting stations significantly increases with time, until tsunami energetics fully exit the near-field. The critical propagation thresholds appears as elbows in Fig. 11 and are specific to each model. Such thresholds correspond to the times after which the increase in the number of detecting stations is mostly due to the propagation of tsunami along the trench. The vertical dashed lines in Fig. 11 show approximate positions of these thresholds. 


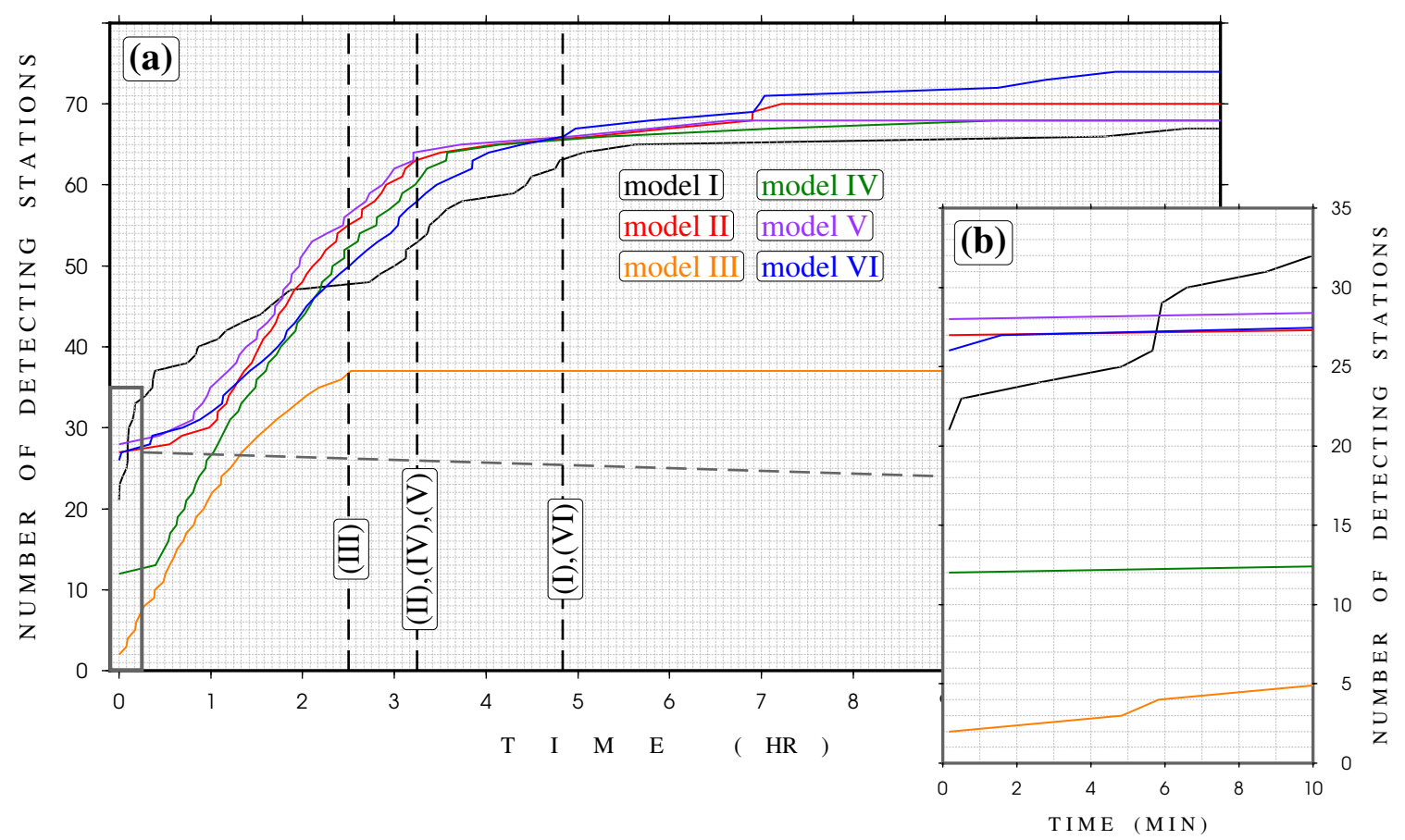

Figure 11: (a) Cumulative number of stations detecting the tsunami over simulation time. Each scenario is shown by a different color. Vertical dashed lines show approximate times of elbows (change in the trend of increase) for the labeled models; (b) zoomed view of the area inside the gray box in (a) to highlight first detection. Note the change in time scale. The nonzero start of the curves is due to the static nature of sources.

With the exception of model III, tsunamis from each of our rupture scenarios are going to be sampled by at least 60 SMART stations, corresponding to a geographic span of $\sim 5000 \mathrm{~km}$. For the case of model III, there is no increase in the number of recording stations (47) beyond $2 \mathrm{hr} 30 \mathrm{~min}$ after the origin time. However, we note that such a sharp change of behavior can be used as an excellent constraint on the source dimensions and thus is a good measure of the tsunami hazard. Indian Ocean tsunami warning guidelines, in fact, suggest caution after a similar alarm window for coastal communities after the first tsunami warning (IOTWS, 2007).

Addition of the proposed SMART array will therefore provide a major improvement in the necessary knowledge to provide a more comprehensive understanding of the source mechanism, in both near- and far-field, especially in the case of complex 
ruptures. The product will be higher resolution maps of both earthquake source and tsunami propagation similar to the role of DART sensors in the case of 22 July $2020 M_{w}$ 7.8 Shumagin earthquake by providing an extra set of temporal and spatial constraints (Ye et al., 2021).

\subsubsection{Landslide Tsunamis}

Similar to the case of earthquake source scenarios, we investigate the coverage of landslide tsunamis by the SMART stations. Here, we do not consider the DART stations due to (a) their large distance to landslides, and (b) the fast decay of these tsunamis as their higher frequency content would lead to more significant attenuation, resulting in practically nonexisting far-field amplitudes (Geist \& Parsons, 2009).

Fig. 12a shows the cumulative number of SMART stations detecting the tsunamis from the slides in Figs. 8 and 9 over 30 minutes of simulation time. Each curve in Fig. 12a belongs to a landslide tsunami scenario, color-coded according to the longitude of source. As seen from the clustering of colors, the diagonal dashed line which separates the two apparent trends in the diagram coincides with the approximate transition between Sumatra (in the west) and Java (in the east).

Therefore, Fig. 12a shows that tsunamis in Java arrive significantly later than their Sumatran counterparts. As can be seen in Fig. 8b, this phenomenon is an effect of larger distances of the landslide scenarios for Java from the Trench. The (mainly three) low-longitude curves in the Java cluster in Fig. 12a belong to the slide sources located at the far northern end of the Sumatran island and on the complex back-arc bathymetry of the Andaman island chain.

The relatively consistent slope of curves in Fig. 12a as shown in $12 \mathrm{~b}$ is due to the small, uniform length scale of sources, compared to the array spacing. The outliers belong to either the southern- or northernmost events which deviate from 
the otherwise uniform trend. Large distances of these slide scenarios, often at either ends of the 1-D SMART array, from stations at the other end contributes to the large delay times in Fig. 12.

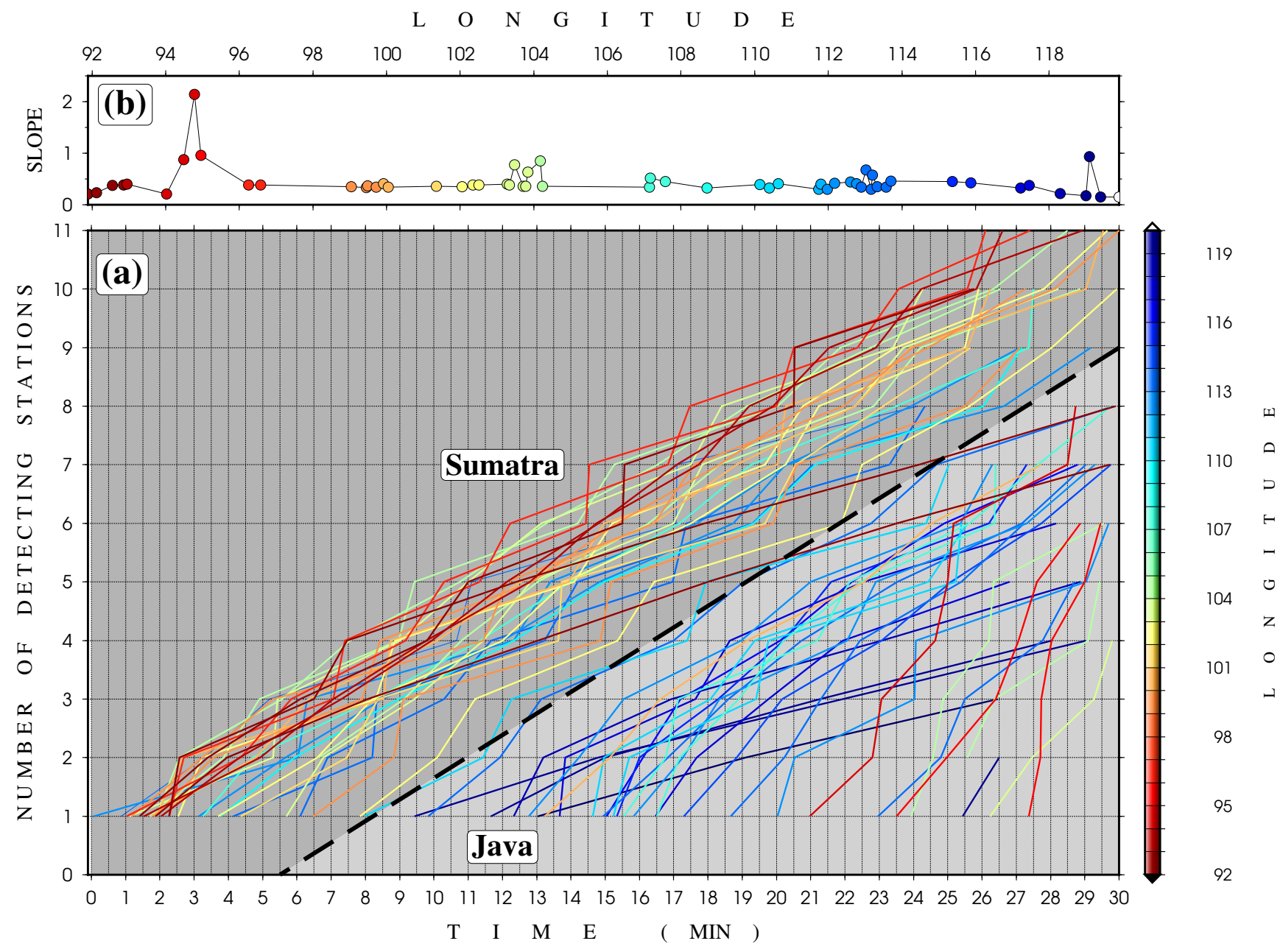

Figure 12: (a) Cumulative number of stations detecting the tsunami from landslides over 30 minutes of simulation time. Each scenario is shown by a different color according to source longitude. Diagonal dashed line shows an approximate transition form western to eastern dipole locations. (b) Slopes of the curves in (a) as a function of source longitude. 


\section{Earthquakes}

Among the most important parameters in earthquake early warning are quick detection of seismic phases, estimation of earthquake magnitude, and locating the hypocenter or centroid. Sparse network coverage can result in considerable uncertainties in each of these components of a successful early warning process. As discussed in section 1.3, such sparsity, for example, hinders quick calculation of these parameters due to late arrival times of seismic phases. Statistical and analytical approaches are typically used to quantify or improve the quality of such biases (Wysession et al., 1991; Lomax et al., 2000; Thurber \& Engdahl, 2000). However, in general terms, a closely spaced seismic network is desired for quick detection of earthquakes.

A large number of earthquake location methods use the arrival time of $\mathrm{P}$-waves. Fig. 13 shows the calculated P-wave arrival times from the six source scenarios in section 3.1, both at existing seismic stations (available via IRIS) and at the proposed SMART stations. In Fig. $13 \tau_{P}$ is the median of P-wave arrival times (from origin time) at stations within a radius of $5^{\circ}$ from the epicenter (due to non-homogeneous geographic distribution of stations, median is more appropriate than other statistical metrics such as the mean). The value for radius is selected as approximately twice the rupture length of an $8.0<M_{w}<8.5$ earthquake as predicted by earthquake scaling laws (e.g., Geller, 1976; Mai \& Beroza, 2000; Thingbaijam et al., 2017). While such a distance is designed to represent the full extent of the source, it is admittedly arbitrary to some extent (see below for further discussion of Fig. 13). 


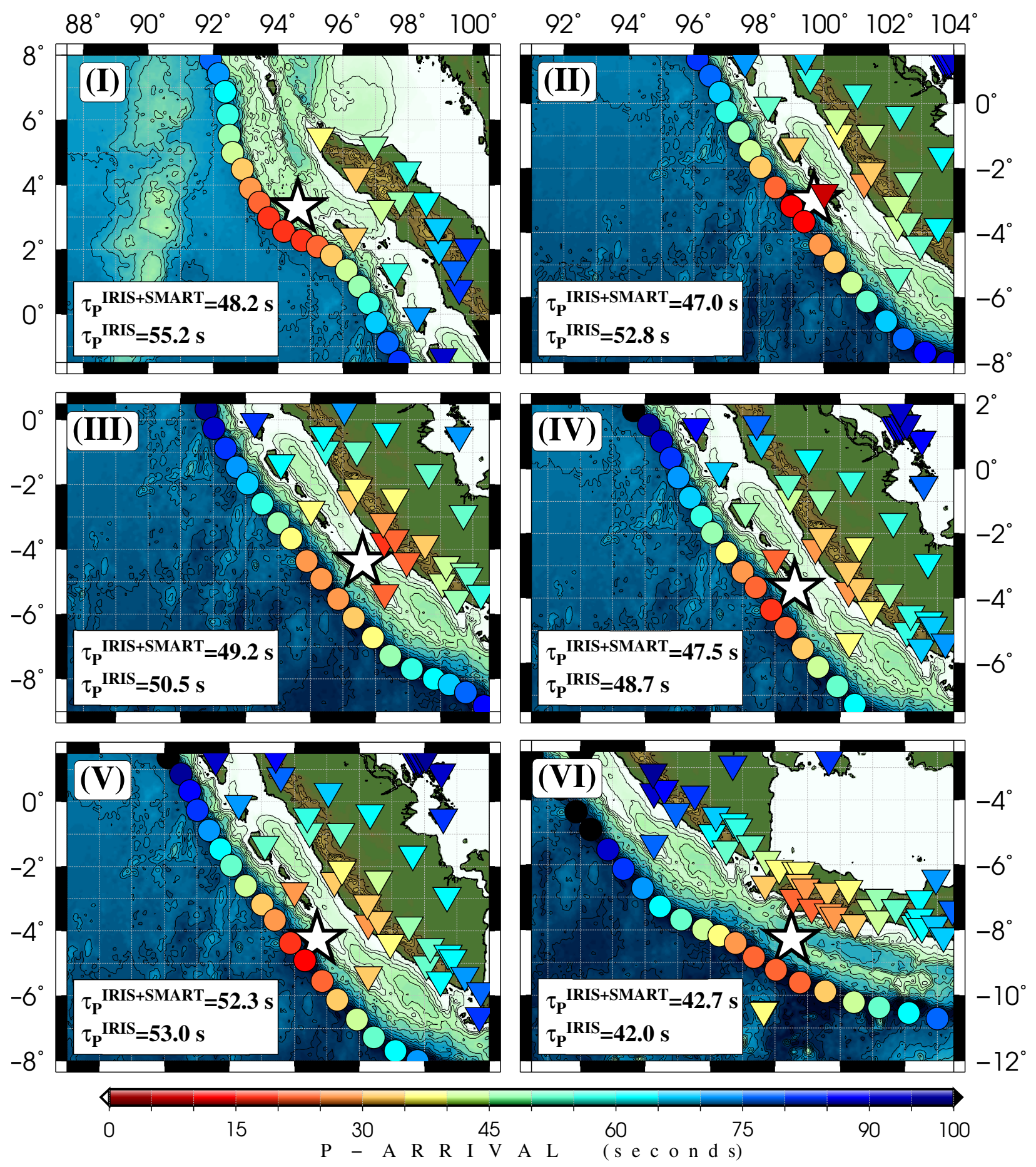

Figure 13: P-wave arrival times from epicenters (white stars) of models I-VI in Fig. 7 at current (i.e., IRIS) and SMART stations. $\tau_{P}$ is the median of P-wave arrival times at stations within a $5^{\circ}$ radius from the source.

The progress in the number of detecting stations for the six scenarios is shown 530 in Fig. 14. In each of Figs. 14I-VI, the blue curves represent cumulative numbers 


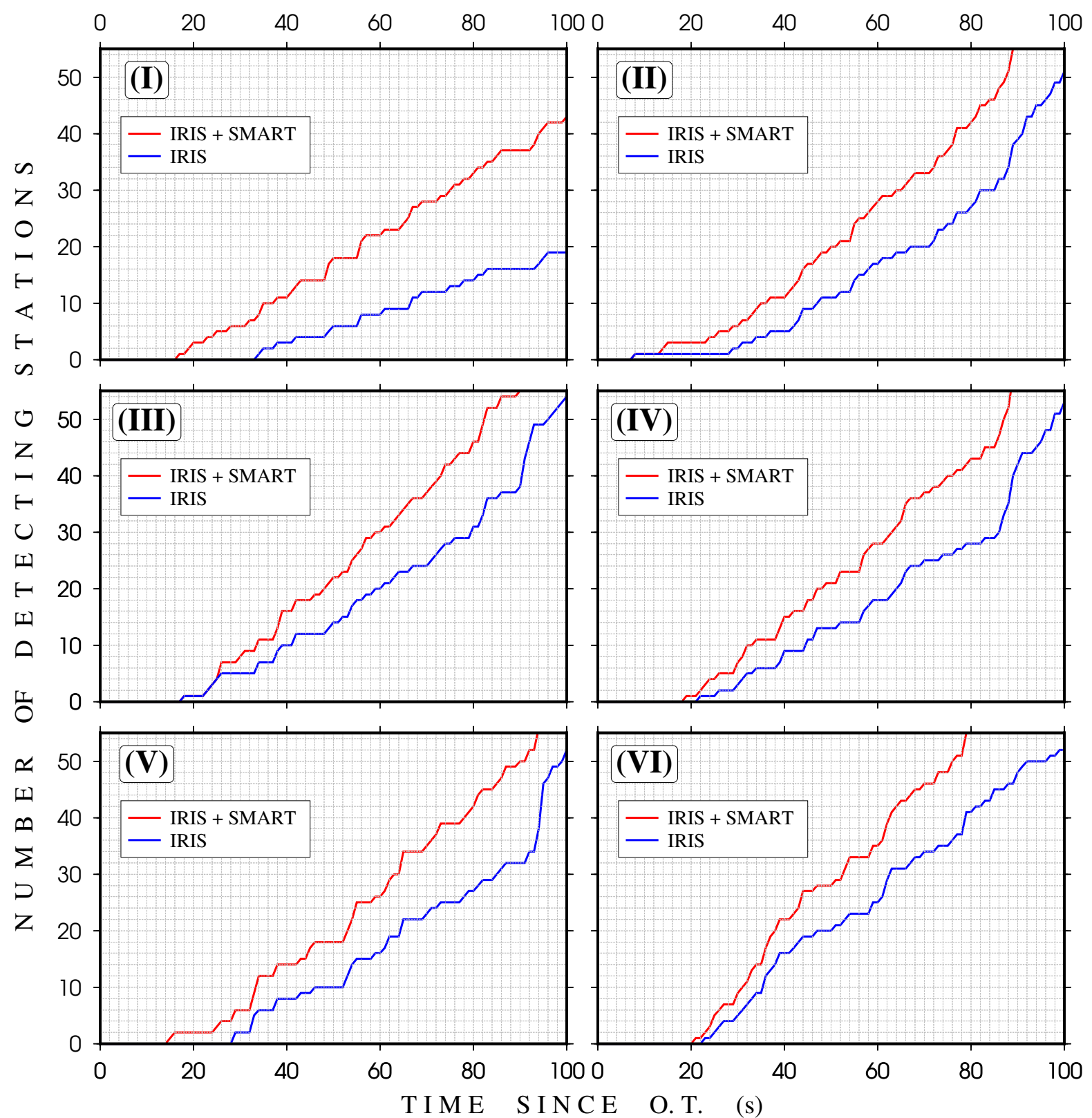

Figure 14: Cumulative number of stations in IRIS (blue) and IRIS+SMART detecting P-waves, over time. I-VI panels represent sources from respective models in Fig. 7.

While P-wave earthquake location methods are usually robust in real-time, sole 

539 in Figs. 13 and 14.

reliance on P-waves can result in considerable location inaccuracies (Rabinowitz, 2000), and thus S-waves are often used to improve location quality. Figs. 15 and

16 show the calculated S-wave arrival times for our six source scenarios (I-VI) and ${ }_{38}$ the respective number of detecting stations in each case, similar to their counterparts 


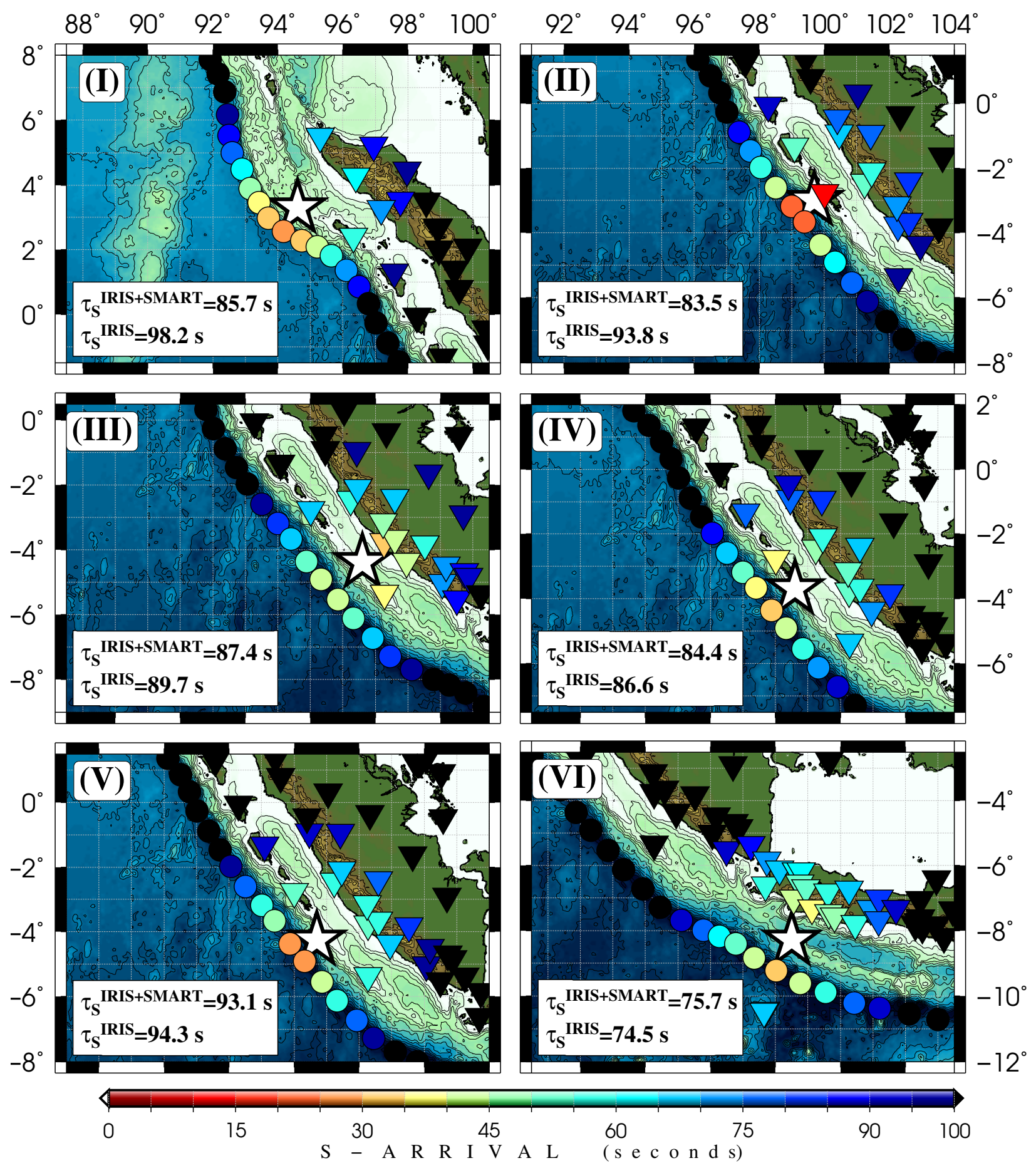

Figure 15: Same as Fig. 13, but for S-waves. 


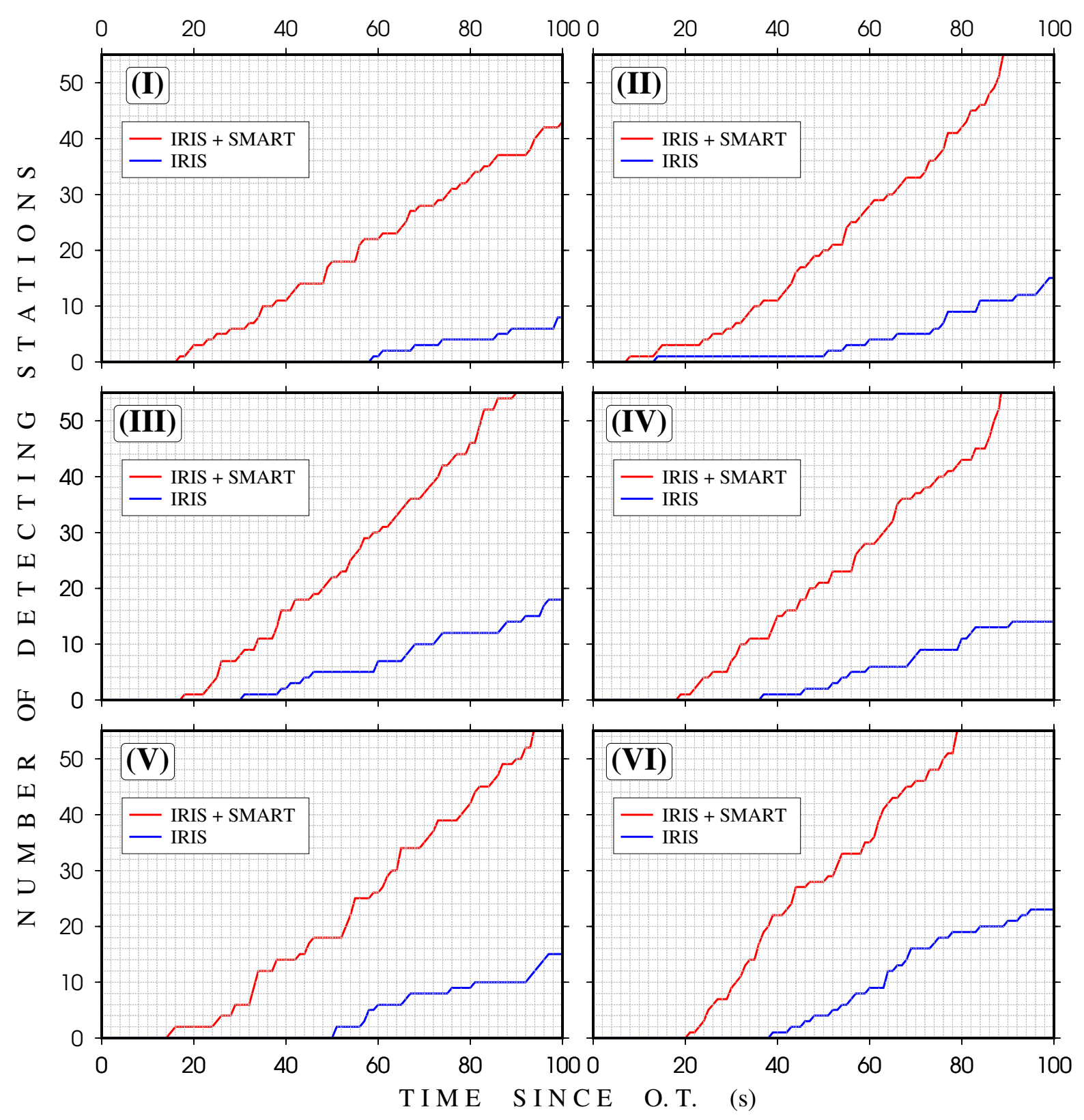

Figure 16: Same as Fig. 14, but for S-waves.

As shown in Fig. 14, addition of SMART stations improves the number of detecting stations (sometimes twice) in the first two minutes after the earthquake origin time. This improvement is more significant for $\mathrm{S}$-waves as shown in Fig. 16. In close vicinity of the earthquake source, detection times of $\mathrm{P}$ and $\mathrm{S}$ waves (as average values of $\tau_{P}$ and $\tau_{S}$ ) by a large number of stations are respectively improved by $2.6 \mathrm{~s}$ and 4.6 s. Table 2 compares these values for both $\mathrm{P}$ and $\mathrm{S}$ waves. 
The outlier to the discussed improvement is the apparent increase in both $\tau_{P}$ and $\tau_{S}$ for the composite source in Java (model VI). We attribute the discrepancy to the closer proximity of earthquake centroid to a dense cluster of onland stations than to SMART cables. We also note that mainland Java is considerably farther from the trench $(>200 \mathrm{~km})$ and thus the SMART stations (addition of farther SMART stations simply adds to the body of larger travel time, thereby increasing the median).

The ratio of difference for $\mathrm{S}$ - and $\mathrm{P}$-waves in Table 2 is $\tau_{S} / \tau_{P} \approx 1.7$, equal to the approximate global ratio of $\mathrm{S}$ - and $\mathrm{P}$-wave shallow velocities for a Poissonian Earth. This implies the difference to be due to the source-receiver geometry. Any further discrepancies in arrival times would be due to lateral slab heterogeneity (e.g., Abercrombie et al., 2001; Bilek \& Engdahl, 2007) which are not accounted for in our simple 1-D velocity model.

Table 2: Detection of seismic phases by the IRIS alone and IRIS+SMART networks.

\begin{tabular}{|c|c|c|c|c|c|c|}
\hline Source Model & \multicolumn{2}{|c|}{$\tau_{P}(\mathrm{~s})$} & $\Delta \tau_{P}(\mathrm{~s})$ & \multicolumn{2}{|c|}{$\tau_{S}(\mathrm{~s})$} & $\Delta \tau_{S}(\mathrm{~s})$ \\
\hline- & IRIS & IRIS+SMART & - & IRIS & IRIS+SMART & - \\
\hline I & 55.2 & 48.2 & 7 & 98.2 & 85.7 & 12.5 \\
\hline II & 52.8 & 47 & 5.8 & 93.8 & 83.5 & 10.3 \\
\hline III & 50.5 & 49.2 & 1.3 & 89.7 & 87.4 & 2.3 \\
\hline IV & 48.7 & 47.5 & 1.2 & 86.6 & 84.4 & 2.2 \\
\hline V & 53 & 52.3 & 0.7 & 94.3 & 93.1 & 1.2 \\
\hline VI & 42 & 42.7 & -0.7 & 74.5 & 75.7 & -1.2 \\
\hline \hline average & 50.4 & 47.8 & 2.6 & 89.5 & 85.0 & 4.6 \\
\hline
\end{tabular}

Figs. 14 and 16 show that with the exception of scenarios II and III, inclusion 
of SMART stations results in the addition of at least two stations within the first 20 seconds from the origin time. As a rule of thumb, quick and successful detection of earthquake location requires at least five seismic stations with a maximum azimuthal gap of $180^{\circ}$ (Howe et al., 2019).

\subsection{Azimuthal Gap}

Azimuthal gap is a traditionally robust measure of network coverage deficiencies. Large azimuthal gaps can create considerable bias in earthquake location results by introducing systematic non-uniformities in arrival times at different azimuths. An azimuthal gap of $120^{\circ}$ in all distances results in mislocation of earthquake by less than $20 \mathrm{~km}$ (Thurber \& Engdahl, 2000). Secondary azimuthal gap is also used to address stations with disproportionately large data importance (Bondár et al., 2004).

The elongated shape of Sumatra, Java and their parallel island chains, and consequently their native seismic stations imposes an inevitably large seismic gap, at times reaching $\sim 180^{\circ}$. Fig. 17 shows the distribution of azimuthal gaps for the USGS catalog of Sumatra and Java earthquakes (Fig. 18). As shown in Fig. 17, the addition of SMART stations, significantly reduces the median of network azimuthal gap, i.e. by $135^{\circ}$ (from $187^{\circ}$ to $52^{\circ}$ ). This is achieved by closing the west-side azimuthal gap by a linear, closely packed array of stations. Obviously the earthquakes at the two ends of the array will still be exposed to relatively large values of azimuthal gap, although to a lesser degree, as shown in Fig. 18a-b. We note that there are still a small number of earthquakes with large values of azimuthal gap west of the SMART array (Fig. 18b). The majority of these earthquakes are either small $(\widetilde{M}=4.5)$ or have strike-slip mechanism (for instance, the $M>8$ duo in April 2012). In both cases, they are far away from land and therefore do not impose significant seismic or tsunami hazard to the population centers in the region (see Fig. 2). 


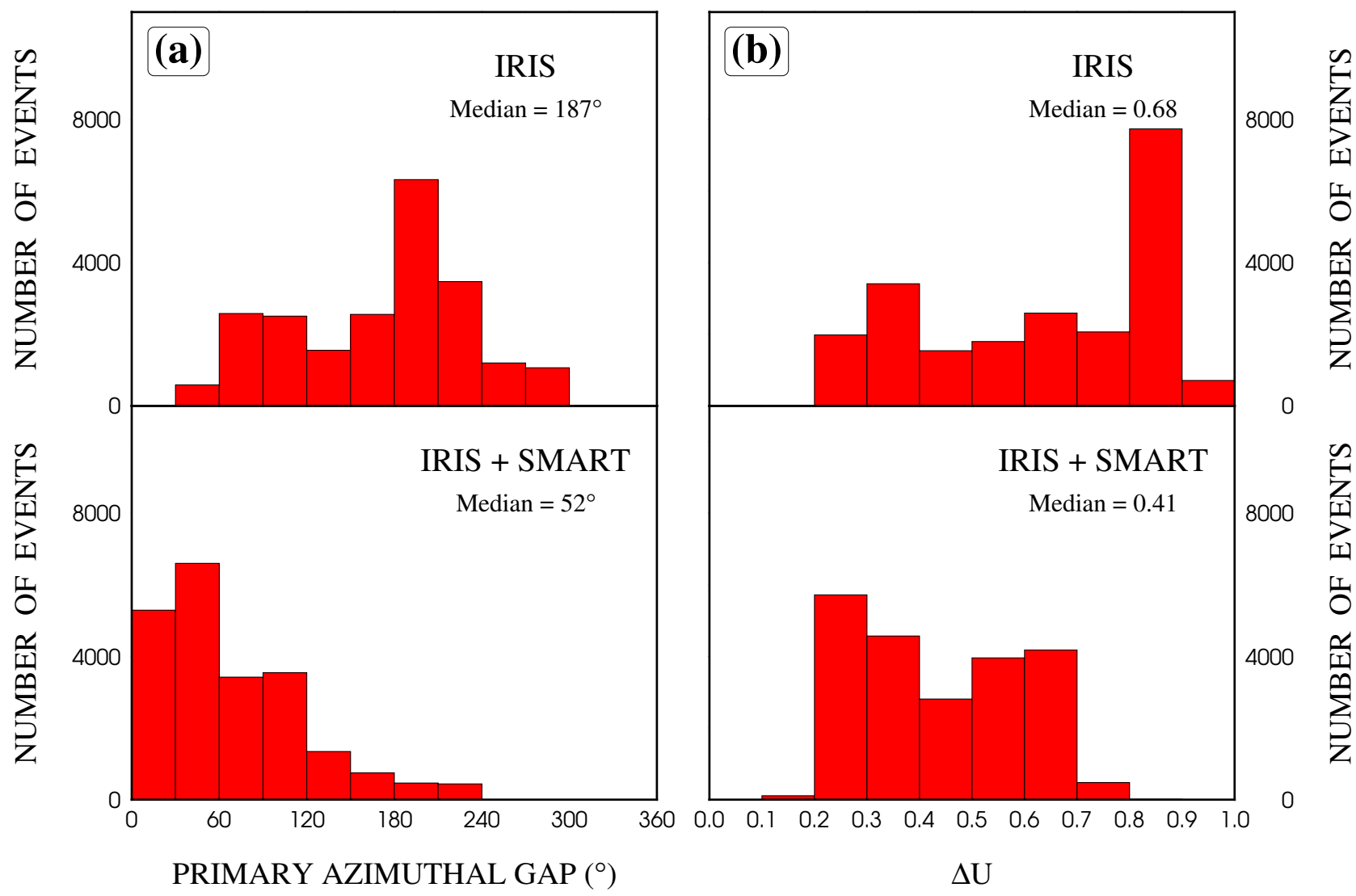

Figure 17: Distribution of (a) primary azimuthal gap and (b) $\Delta U$ for the USGS catalog of Sumatra (Fig. 18) before (top) and after (bottom) addition of SMART stations. 


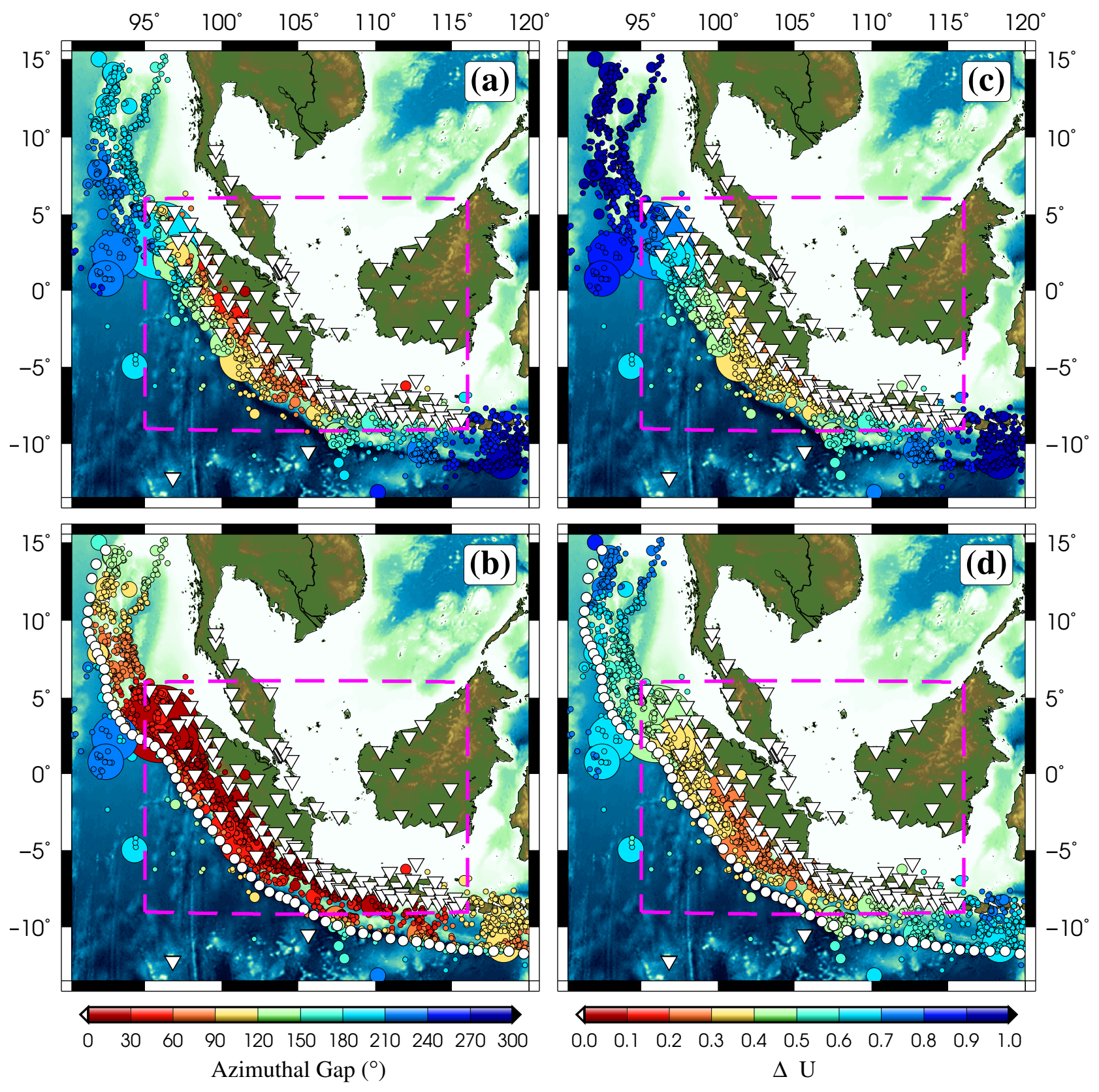

Figure 18: [Left] $\Delta U$ calculated for the USGS events $(M \geq 4$ and $H<40 \mathrm{~km})$ using the seismic network (a) before, and (b) after addition of SMART stations. [Right] Primary azimuthal gap for the same events (c) before, and (d) after addition of SMART stations. The area shown by the dashed rectangle marks the events closer to populated parts of Sumatra and Java (see Figs. 2 and 19.)

\section{$4.2 \Delta U$}

While azimuthal gap is a robust measure of angular completeness of network coverage it does not provide any insight on the spacing of the seismic network. Large 
epicentral distance to seismic stations, especially in the case of offshore earthquakes can significantly hinder the detection and location processes, as demonstrated in Fig. 13VI for our Java source model. Similarly, non-uniform distribution of stations may result in poor constraints on calculation of a valid rupture models for any given earthquake (Saraò et al., 1998).

To address this issues, we adopt the parameter $\Delta U$ introduced by Bondár \& McLaughlin (2009) as network quality metric. This parameter is a geometrical expression for spatial distribution of stations in a given seismic network. $\Delta U$ ranges between 0 and 1 for respectively good and bad network coverage regarding a given earthquake. While there is no distance term in the $\Delta U$ algorithm, the relative azimuthal coverage built into $\Delta U$ implicitly provides a measure of spatial proximity of the stations.

We also recall that the original algorithm for calculation of $\Delta U$ was prescribed for networks in small geographic settings $(D<150 \mathrm{~km})$. We therefore confine our calculations for each event to stations within a radius of 10 times the median of network spacing (median of $0.9^{\circ}$ for the current network and $1.2^{\circ}$ with the addition of SMART stations). Such a radius is admittedly large considering the framework of the original algorithm. However, this choice was made due to the properties of active subduction zones such as Sumatra and Java wherein the rupture length can no longer be ignored within the network - as was assumed to be the case in the original $\Delta U$ algorithm. While this constraint is somewhat arbitrary (although fits well within the framework of regional seismology (Havskov et al., 2011)), it would result in the inclusion of large source as well as at least about five stations for each earthquake in our dataset.

Fig. 17b compares the distribution of $\Delta U$ for the USGS events in the region with and without the inclusion of our proposed SMART stations. Addition of these 
SMART stations improves the earthquake location performance by almost $40 \%$ (from $\Delta U=0.68$ to $\Delta U=0.41)$. While the original good/bad quality threshold from $\Delta U$ values - which were obtained by regression to a large dataset of ground truth events - are no longer valid in our modified algorithm, one must note that abundance of smaller values of $\Delta U$ would inevitably correspond to higher location quality. Thus, a narrower distribution of $\Delta U$ around a considerably smaller value as a result of the deployment of SMART stations is a significant improvement.

Similar to the case of azimuthal gaps, the remaining large $\Delta U$ values are in the NW and SE ends of the network as shown in Figs. 18c-d. These events must be taken into account in a comprehensive study of detection contribution of any additional array. However, we should note that they are mostly either small or located near less populated parts of the region. Repeating the calculations for only the events closer to populated sites which are incidentally located inside the best covered areas, significantly improves both azimuthal gap and $\Delta U$ distributions as shown in Fig. 19. 


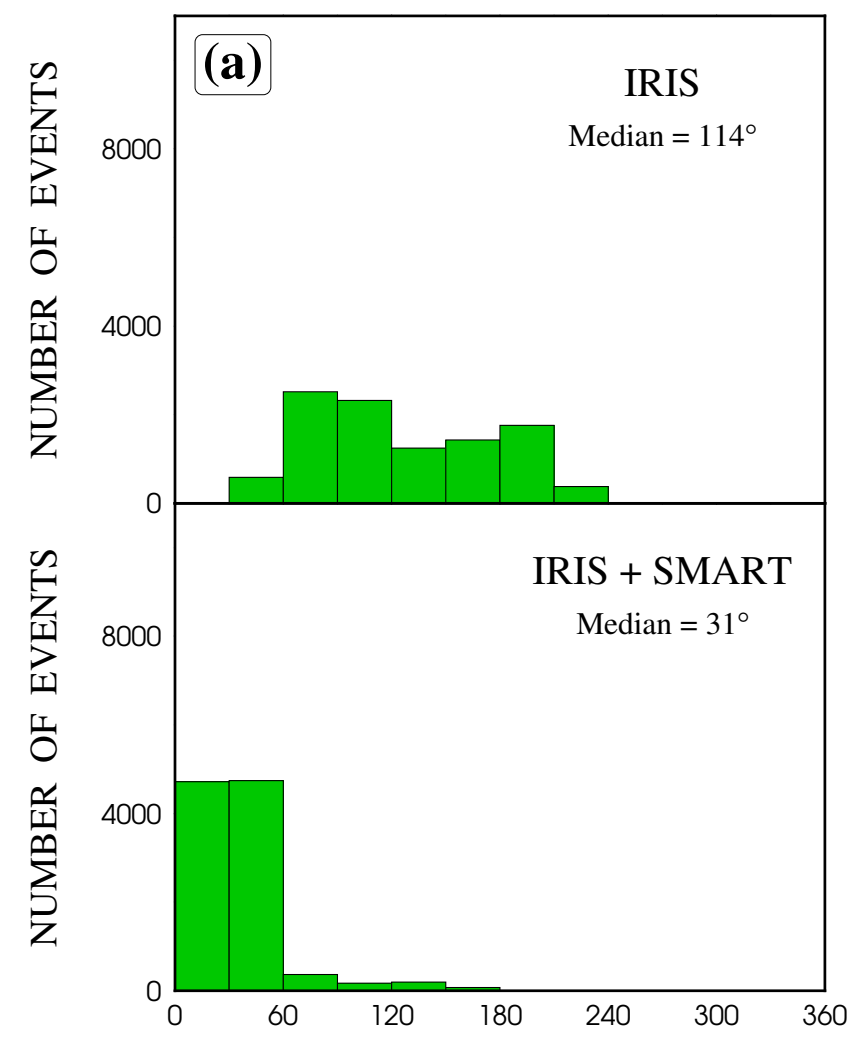

PRIMARY AZIMUTHAL GAP $\left({ }^{\circ}\right)$

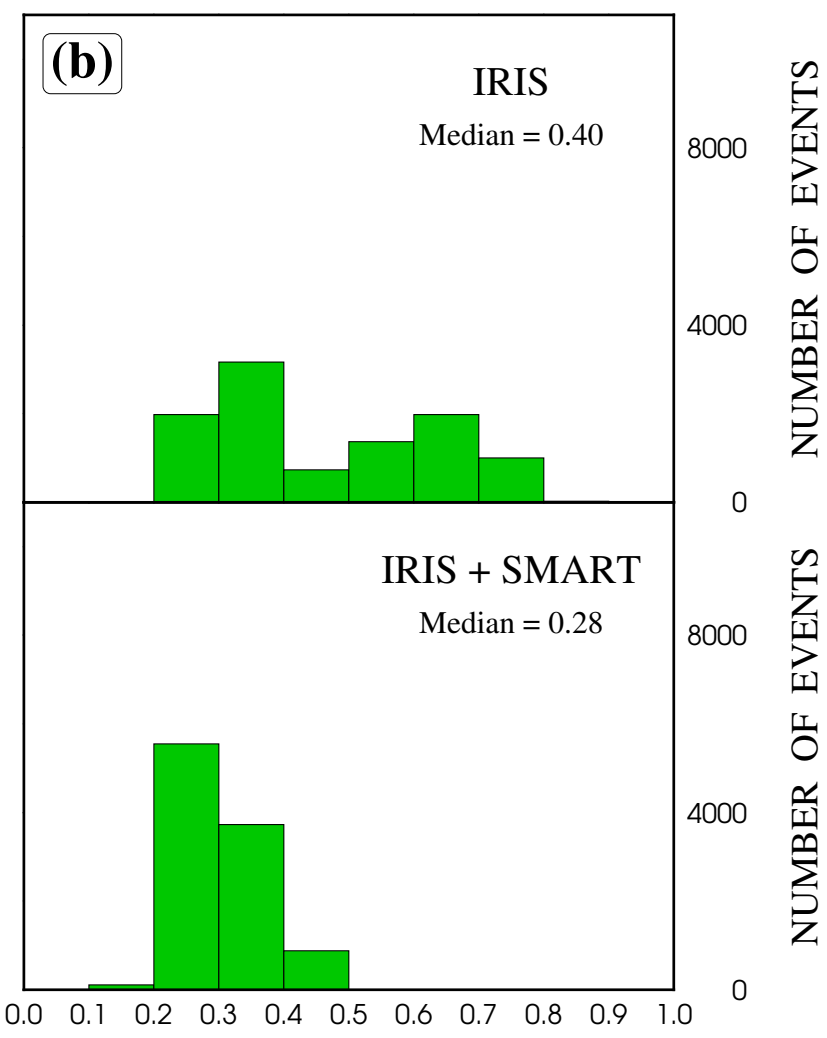

$\Delta \mathrm{U}$

Figure 19: Similar to Fig. 17, but for the smaller, more populated geographic area marked by the dashed rectangle in Fig. 18 .

\section{Discussion and Conclusions}

Our exploratory study of a potential SMART cables system in Sumatra and Java (Fig. 3) shows that such a network can significantly improve the current capability in monitoring earthquake and tsunami hazard. This is particularly important considering the highly populated areas in the region (Fig. 2).

Calculated arrival times for seismic phases show that addition of an off-trench SMART array of 76 stations can decrease the median detection and locating time of earthquakes by up to $\sim 7 \mathrm{~s}$ and $\sim 12 \mathrm{~s}$ for P- and S-waves, respectively (average of 2.6 and 4.6 s improvements; Table 2). Fig. 14 shows that within the first 20 seconds after the earthquake origin time, such a SMART array can contribute at least two 
stations more than the the existing seismic network to the detection of P-waves. This contribution reaches $\sim 10$ stations for S-waves (Fig. 16). The relatively different arrival times at stations 51 to 76 is due to their larger distance from the trench. We recall that these stations were positioned to monitor and study the seismic and tsunami hazard in the Arafura Sea and northwestern Australia, and not based on the geological merits of their whereabouts.

The addition of proposed stations will also improve any further modeling of seismic sources in the region by providing a larger set of available seismic data and thus in the long term serve to better understand the seismic and corresponding tsunami risk. We must also note that azimuthal distribution and the positioning of the stations relative to the direction of rupture propagation are more important than merely the number of station (Saraò et al., 1998). An inevitably large azimuthal gap (with a median of $\sim 190^{\circ}$; Figs. 17a) in the existing onland seismic network is resulted from the elongated character of Sumatra and Java (Fig. 3). Such a large gap has dire implications on accurately pinpointing seismic hypocenters in space and time. A robust solution to this issue is the deployment of offshore stations. Our proposed off-trench SMART stations are excellent candidates in this regard as they would almost entirely close the large, west-side azimuthal gap for future subduction zone earthquakes (Figs. 17a). Naturally, the improvement to the network is more significant away from its two ends in the NW and SE. In fact, the stations in the vicinity of more populated areas, i.e., in the central $\sim 4000 \mathrm{~km}$ of the array (the pink, dashed rectangle in Fig. 18), include much smaller gaps, statistically $<60^{\circ}$ (Fig. 19a).

Application of a slightly modified version of Bondár \& McLaughlin's (2009) $\Delta U$ algorithm to a network comprised of existing seismic stations and the off-trench SMART array reaches a similar conclusion. Our calculations show that the inclusion of an off-trench SMART array can reduce the value of $\Delta U$ by $40 \%$, down to 0.41 
(Fig. 17b). The moderate value of $\Delta U$ shows that even in the presence of SMART array, the network still suffers from a non-homogeneous distribution of stations. However (similar to the situation with azimuthal gap), for only the events along the main islands of Sumatra and Java, $\Delta U$ is reduced to 0.28. This shows that for practical purposes (close to the populated areas), inclusion of SMART stations improves the location and detection processes per standards used in earthquake early warning (Fig. $19 b)$.

Our simulation of tsunamis from six potential earthquake ruptures (Figs. 6 and 7 and Table 1) show major improvement in detection of tsunamis by the offtrench SMART network compared to the only existing offshore monitoring system, i.e., DART stations in the northwest (Figs. 3 and 7) at times by several hours (Figs. 10 and 11).

We also simulate tsunamis from 58 potential submarine landslide scenarios designed from analyses of bathymetric slope and calculated PGA from existing earthquake catalogs (Fig. 8). These simulations show Sumatran and Javanese landslide tsunamis have relatively different trends (Fig. 12) with Sumatran events being detected earlier by the SMART network. This is due to the closer proximity of slopes and hence the designed landslides to the array, compared to the situation in Java. Tsunamis from the Sumatran landslide scenarios (hot colors in Fig. 12) are mostly detected by at least 4 SMART stations within 10 minutes after origin time. This is while the tsunamis from scenarios near Java require twice that time ( $\sim 20$ minutes) for detection by the same number of stations.

Tsunamis from these events can reach shorelines of Sumatra and Java within $\sim 30$ minutes. Thus, in the absence of any other reliable detection network in the region, such detection times are extremely valuable for issuing tsunami warning in the future. 
In the final analysis, our study shows with repeaters (nodes) at every 50-120 $\mathrm{km}$, a SMART cable system similar to our proposed array will considerably improve fast detection of earthquakes and tsunamis (with tectonic and non-tectonic sources) in the region. Therefore, deployment of these systems can play a significant role in earthquake and tsunami early warning. We note that as new tsunami sensors (e.g., DART stations) are added and with the advent of new technology (e.g., Hossen et al., 2021) these same or similar calculations can be repeated.

We would expect other countries in the region subjected to the risk of Indonesia events to be partners in this regional system, also building up their own national systems in a similar way to create an integrated and unified large regional system. The mere $5 \%$ contribution dealing with rapid detection of hazards in the $45^{\text {th }}$ Annual Conference of Indonesian Association of Geophysicists (Sakya, 2020) shows the dire need for attention to the planning of such systems. The UNESCO-IOC - through collaboration with its Indian Ocean Tsunami Warning System (IOTWS) and the Pacific Tsunami Warning and Mitigation System (PTWS) - and the World Meteorological Organization (WMO) must be involved. Coordination can be facilitated by the IOC International Tsunami Information Center(ITIC), the Indian Ocean Tsunami Information Center (IOTIC), and the overarching Working Group on Tsunamis and Other Hazards Related to Sea-Level Warning and Mitigation Systems (TOWS-WG). Simple calculations of the approximate cost for our proposed SMART array using basic assumptions (e.g., one time telecom cost of $\$ 40,000 / \mathrm{km}$ and SMART/early warning incremental cost of $\$ 4,000 / \mathrm{km}$; Joint Task Force on SMART Cable Systems, personal comm.) is $\sim \$ 350$ million which is only a small fraction of the economic loss $(\$ 4.45$ billion; Athukorala \& Resosudarmo, 2005) from the 2004 tsunami and earthquake. Efforts will be required to obtain development bank funding and other foreign aid to complement direct government and commercial funding. 
715

\section{Acknowledgments}

The project significantly benefited from frequent and constructive discussions with Bill Fry and Luis Matias. We are grateful to Michael Hamilton for providing coordinates of existing global telecom cables. Amir Salaree and Yihe Huang were supported at University of Michigan by the National Science Foundation grant, PREEVENTS geosciences directorate No. 1663769. Bruce Howe was supported by NASA (via JPL) Award NNN13D462T. Several figures were created using Generic Mapping Tools (Wessel \& Smith, 1998).

\section{Declarations}

\section{Funding:}

Amir Salaree and Yihe Huang were supported at University of Michigan by the National Science Foundation grant PREEVENTS geosciences directorate No. 1663769.

Bruce Howe was supported by NASA (via JPL) Award NNN13D462T.

\section{Conflicts of Interest/Competing Interests:}

The authors declare that they do not have any competing interests.

\section{Availability of Data and Material:}

Bathymetry data is available via NOAA at https://www.ngdc.noaa.gov/mgg/ global/ and https://www.ngdc.noaa.gov/mgg/fliers/06mgg01.html. Array data and visualization information are available via Deep Blue Data at https://doi.org/ 10.7302/0jmy-pa60. 
Code Availability:

TauP (used to calculate seismic arrival times) is available at https://www.seis . 738 Sc.edu/taup/. The tsunami simulation code is maintained and distributed by NOAA

739 (https://nctr.pmel.noaa.gov/nthmp/). 


\section{References}

Abercrombie, R. E., Antolik, M., Felzer, K., \& Ekström, G., 2001. The 1994 Java tsunami earthquake: Slip over a subducting seamount, Journal of Geophysical Research: Solid Earth, 106(B4), 6595-6607.

Allen, R. M., Kong, Q., \& Martin-Short, R., 2020. The Myshake Platform: A global vision for earthquake early warning, Pure and Applied Geophysics, 177, 1699-1712.

Amante, C. \& Eakins, B. W., 2009. ETOPO1 arc-minute global relief model: Procedures, data sources and analysis, NOAA, NESDIS(NGDC-24), 25pp.

Ammon, C. J., Ji, C., Thio, H.-K., Robinson, D., Ni, S., Hjorleifsdottir, V., Kanamori, H., Lay, T., Das, S., Helmberger, D., et al., 2005. Rupture process of the 2004 Sumatra-Andaman earthquake, Science, 308(5725), 1133-1139.

Angove, M., Arcas, D., Bailey, R., Carrasco, P., Coetzee, D., Fry, B., Gledhill, K., Harada, S., von Hillebrandt-Andrade, C., Kong, L., et al., 2019. Ocean observations required to minimize uncertainty in global tsunami forecasts, warnings, and emergency response, Frontiers in Marine Science, 6, 350.

Anugrah, S. D. \& Sunardi, B., 2012. Seismic activity and tsunami potential in BaliBanda Basin, in Proceedings of the 3rd International Conference on Sustainable Built Environment, Melbourne: ICSBE, pp. 1-10.

Aoi, S., Asano, Y., Kunugi, T., Kimura, T., Uehira, K., Takahashi, N., Ueda, H., Shiomi, K., Matsumoto, T., \& Fujiwara, H., 2020. MOWLAS: NIED observation network for earthquake, tsunami and volcano, Earth, Planets and Space, 72(1), $1-31$.

Athukorala, P.-c. \& Resosudarmo, B. P., 2005. The Indian Ocean tsunami: Economic impact, disaster management, and lessons, Asian economic papers, 4(1), 1-39. 
Barros, J. S., 2019. Atlantic submarine cable platform: A smart, green \& blue approach, Submarine Networks EMEA 2019, [London 12-13 February 2019].

Ben-Menahem, A. \& Rosenman, M., 1972. Amplitude patterns of tsunami waves from submarine earthquakes, Journal of Geophysical Research, 77(17), 3097-3128.

Benioff, H., 1949. Seismic evidence for the fault origin of oceanic deeps, Geological Society of America Bulletin, 60(12), 1837-1856.

Bilek, S. L. \& Engdahl, E. R., 2007. Rupture characterization and aftershock relocations for the 1994 and 2006 tsunami earthquakes in the Java subduction zone, Geophysical Research Letters, 34(20).

Bondár, I. \& McLaughlin, K., 2009. A new ground truth data set for seismic studies, Seismological Research Letters, 80(3), 465-472.

Bondár, I., Myers, S. C., Engdahl, E. R., \& Bergman, E. A., 2004. Epicentre accuracy based on seismic network criteria, Geophysical Journal International, 156(3), 483496.

Borrero, J. C., Sieh, K., Chlieh, M., \& Synolakis, C. E., 2006. Tsunami inundation modeling for western Sumatra, Proceedings of the National Academy of Sciences, 103(52), 19673-19677.

Borrero, J. C., Weiss, R., Okal, E. A., Hidayat, R., Arcas, D., \& Titov, V. V., 2009. The tsunami of 2007 September 12, Bengkulu province, Sumatra, Indonesia: Posttsunami field survey and numerical modelling, Geophysical Journal International, 178(1), 180-194.

Brune, S., Babeyko, A., Ladage, S., \& Sobolev, S. V., 2010. Landslide tsunami hazard in the Indonesian Sunda Arc, Natural Hazards and Earth System Sciences (NHESS), 10(3), 589-604. 
Buland, R. \& Chapman, C., 1983. The computation of seismic travel times, Bulletin of the Seismological Society of America, 73(5), 1271-1302.

Burbidge, D., Cummins, P. R., Mleczko, R., \& Thio, H. K., 2008. A probabilistic tsunami hazard assessment for Western Australia, in Tsunami Science Four Years after the 2004 Indian Ocean Tsunami, pp. 2059-2088, Springer.

Campbell, K. W. \& Bozorgnia, Y., 2003. Updated near-source ground-motion (attenuation) relations for the horizontal and vertical components of peak ground acceleration and acceleration response spectra, Bulletin of the Seismological Society of America, 93(1), 314-331.

Carrier, G. F., 1991. Tsunami propagation from a finite source, in Proc. 2nd UJNR Tsunami Workshop, pp. 101-115, NGDC Hawaii.

Courant, R., Friedrichs, K., \& Lewy, H., 1928. Über die partiellen Differenzengleichungen der mathematischen Physik, Mathematische Annalen, 100(1), 32-74.

Crotwell, H. P., Owens, T. J., \& Ritsema, J., 1999. The TauP Toolkit: Flexible seismic travel-time and ray-path utilities, Seismological Research Letters, 70(2), $154-160$

Duputel, Z., Rivera, L., Kanamori, H., \& Hayes, G., 2012. W phase source inversion for moderate to large earthquakes (1990-2010), Geophysical Journal International, $189(2), 1125-1147$.

Dziewonski, A., Chou, T.-A., \& Woodhouse, J. H., 1981. Determination of earthquake source parameters from waveform data for studies of global and regional seismicity, Journal of Geophysical Research: Solid Earth, 86(B4), 2825-2852.

Dziewonski, A. M. \& Anderson, D. L., 1981. Preliminary reference Earth model, Physics of the Earth and Planetary Interiors, 25(4), 297-356. 
Ekström, G., Nettles, M., \& Dziewoński, A., 2012. The global CMT project 20042010: Centroid-moment tensors for 13,017 earthquakes, Physics of the Earth and Planetary Interiors, 200, 1-9.

Fujii, Y. \& Satake, K., 2007. Tsunami source of the 2004 Sumatra-Andaman earthquake inferred from tide gauge and satellite data, Bulletin of the Seismological Society of America, 97(1A), S192-S207.

Geist, E. L. \& Parsons, T., 2009. Assessment of source probabilities for potential tsunamis affecting the US Atlantic coast, Marine Geology, 264(1-2), 98-108.

Geller, R. J., 1976. Scaling relations for earthquake source parameters and magnitudes, Bulletin of the Seismological Society of America, 66(5), 1501-1523.

Green, G., 1838. On the motion of waves in a variable canal of small depth and width, Transactions of the Cambridge Philosophical Society, 6, 457.

Grilli, S. T., Tappin, D. R., Carey, S., Watt, S. F., Ward, S. N., Grilli, A. R., Engwell, S. L., Zhang, C., Kirby, J. T., Schambach, L., et al., 2019. Modelling of the tsunami from the December 22, 2018 lateral collapse of Anak Krakatau volcano in the Sunda Straits, Indonesia, Scientific reports, 9(1), 1-13.

Hamzah, L., Puspito, N. T., \& Imamura, F., 2000. Tsunami catalog and zones in Indonesia, Journal of Natural Disaster Science, 22(1), 25-43.

Harbitz, C. B., Løvholt, F., \& Bungum, H., 2014. Submarine landslide tsunamis: How extreme and how likely?, Natural Hazards, 72(3), 1341-1374.

Havskov, J., Ottemöller, L., Trnkoczy, A., \& Bormann, P., 2011. Seismic Networks, in Instrumentation in Earthquake Seismology, pp. 211-257, Springer, [version August 2011].

Heidarzadeh, M., Muhari, A., \& Wijanarto, A. B., 2019. Insights on the source of 
the 28 September 2018 Sulawesi tsunami, Indonesia based on spectral analyses and numerical simulations, Pure and Applied Geophysics, 176(1), 25-43.

Hill, E. M., Borrero, J. C., Huang, Z., Qiu, Q., Banerjee, P., Natawidjaja, D. H., Elosegui, P., Fritz, H. M., Suwargadi, B. W., Pranantyo, I. R., Li, L., Macpherson, K. A., Skanavis, V., Synolakis, C. E., \& Sieh, K., 2012. The $2010 M_{w} 7.8$ Mentawai earthquake: Very shallow source of a rare tsunami earthquake determined from tsunami field survey and near-field GPS data, Journal of Geophysical Research: Solid Earth, 117(B6).

Hilmo, R. \& Wilcock, W. S., 2020. Physical sources of high-frequency seismic noise on Cascadia Initiative ocean bottom seismometers, Geochemistry, Geophysics, Geosystems, 21(10), e2020GC009085.

Horspool, N., Pranantyo, I., Griffin, J., Latief, H., Natawidjaja, D., Kongko, W., Cipta, A., Bustaman, B., Anugrah, S., \& Thio, H., 2014. A probabilistic tsunami hazard assessment for Indonesia, Natural Hazards and Earth System Sciences, 14(11), 3105-3122.

Hossen, M., Mulia, I. E., Mencin, D., \& Sheehan, A. F., 2021. Data assimilation for tsunami forecast with ship-borne GNSS data in the Cascadia subduction zone, Earth and Space Science, 8(3), e2020EA001390.

Howe, B. M., Arbic, B. K., Aucan, J., Barnes, C., Bayliff, N., Becker, N., Butler, R., Doyle, L., Elipot, S., Johnson, G. C., et al., 2019. SMART cables for observing the global ocean: Science and implementation, Frontiers in Marine Science, 6, 424.

IOC, 2009. Five years after the tsunami in the Indian Ocean, From strategy to implementation - Advancements in global early warning systems for tsunamis and other ocean hazards 2004-2009, UNESCO Digital Library, Document Code: $\mathrm{IOC} / \mathrm{BRO} / 2009 / 4$ 
IOC et al., 2020. Sea level station monitoring facility, Intergovernmental Oceanographic Commission.

IOTWS, 2007. Tsunami warning center reference guide, U.S. Indian Ocean Tsunami Warning System Program.

IRIS, 2020. Query to view seismic stations on the map, Incorporated Research Institutions for Seismology, http://ds.iris.edu/gmap/\#network=_ OBSIP\&planet=earth [accessed on 07 Dec 2020].

Ishii, M., Shearer, P. M., Houston, H., \& Vidale, J. E., 2005. Extent, duration and speed of the 2004 Sumatra-Andaman earthquake imaged by the Hi-Net array, Nature, 435(7044), 933-936.

Kanamori, H., 2006. Lessons from the 2004 Sumatra-Andaman earthquake, Philosophical Transactions of the Royal Society A: Mathematical, Physical and Engineering Sciences, 364(1845), 1927-1945.

Kopp, H., Flueh, E. R., Petersen, C. J., Weinrebe, W., \& Wittwer, A., 2006. The Java margin revisited: Evidence for subduction erosion off Java, Earth and Planetary Science Letters, 242(1-2), 130-142.

Kurita, T., Arakida, M., \& Colombage, S. R., 2007. Regional characteristics of tsunami risk perception among the tsunami affected countries in the Indian Ocean, Journal of Natural Disaster Science, 29(1), 29-38.

Lay, T., Kanamori, H., Ammon, C. J., Nettles, M., Ward, S. N., Aster, R. C., Beck, S. L., Bilek, S. L., Brudzinski, M. R., Butler, R., et al., 2005. The great SumatraAndaman earthquake of 26 December 2004, Science, 308(5725), 1127-1133.

Lay, T., Ammon, C. J., Kanamori, H., Yamazaki, Y., Cheung, K. F., \& Hutko, A. R., 2011. The 25 October 2010 Mentawai tsunami earthquake $\left(M_{w} 7.8\right)$ and the 
tsunami hazard presented by shallow megathrust ruptures, Geophysical Research Letters, 38(6).

Lomax, A., Virieux, J., Volant, P., \& Berge-Thierry, C., 2000. Probabilistic earthquake location in 3D and layered models, in Advances in seismic event location, pp. 101-134, Springer.

Løvholt, F., Setiadi, N. J., Birkmann, J., Harbitz, C. B., Bach, C., Fernando, N., Kaiser, G., \& Nadim, F., 2014. Tsunami risk reduction - Are we better prepared today than in 2004?, International journal of disaster risk reduction, 10, 127-142.

Mai, P. M. \& Beroza, G. C., 2000. Source scaling properties from finite-fault-rupture models, Bulletin of the Seismological Society of America, 90(3), 604-615.

Mansinha, L. \& Smylie, D., 1971. The displacement fields of inclined faults, Bulletin of the Seismological Society of America, 61(5), 1433-1440.

Matias, L. M., Carrilho, F., Sá, V., Omira, R., Niehus, M., Corela, C., Barros, J., \& Omar, Y., 2021. The contribution of submarine optical fiber telecom cables to the monitoring of earthquakes and tsunamis in the NE Atlantic, Frontiers in Earth Science: Solid Earth Geophysics, [in review].

McCaffrey, R., 2009. The tectonic framework of the Sumatran subduction zone, Annual Review of Earth and Planetary Sciences, 37, 345-366.

McCloskey, J., Lange, D., Tilmann, F., Nalbant, S. S., Bell, A. F., Natawidjaja, D. H., \& Rietbrock, A., 2010. The September 2009 Padang earthquake, Nature Geoscience, 3(2), 70-71.

Meinig, C., Stalin, S. E., Nakamura, A. I., \& Milburn, H. B., 2005. Real-time deepocean tsunami measuring, monitoring, and reporting system: The NOAA DART II description and disclosure, NOAA, Pacific Marine Environmental Laboratory (PMEL), pp. 1-15. 
Mofjeld, H. O., Whitmore, P. M., Eble, M. C., González, F. I., \& Newman, J. C., 2001. Seismic-wave contributions to bottom pressure fluctuations in the North Pacific - Implications for the DART tsunami array, Proc. Int. Tsunami Sym, pp. $5-10$.

Monecke, K., Finger, W., Klarer, D., Kongko, W., McAdoo, B. G., Moore, A. L., \& Sudrajat, S. U., 2008. A 1,000-year sediment record of tsunami recurrence in northern Sumatra, Nature, 455(7217), 1232-1234.

Muhari, A., Imamura, F., Arikawa, T., Hakim, A. R., \& Afriyanto, B., 2018. Solving the puzzle of the September 2018 Palu, Indonesia, tsunami mystery: Clues from the tsunami waveform and the initial field survey data, Journal of Disaster Research, 13(Scientific Communication), sc20181108.

NASA-SEDAC, 2018. Documentation for the Gridded Population of the World, version 4 (GPWv4), Revision 11 Data Sets, Palisades NY: NASA Socioeconomic Data and Applications Center (SEDAC), accessed on 02 Dec 2020.

NGDC/World Data Service, 2021. Global historical tsunami database, NOAA National Centers for Environmental Information, doi:10.7289/V5PN93H7 [accessed on 24 Apr 2021].

Ni, S., Kanamori, H., \& Helmberger, D., 2005. Energy radiation from the Sumatra earthquake, Nature, 434(7033), 582-582.

NOAA, 1993. 5-minute Gridded Global Relief Data (ETOPO5), National Geophysical Data Center, [accessed on 06 Dec 2020].

Nosov, M., 2016. Interpretation of the signals recorded by ocean-bottom pressure gauges, in SMART Submarine Cable Applications in Earthquake and Tsunami Science and Early Warning; Deutsches GeoForschungsZentrum (GFZ), Helmholtzzentrum Potsdam, Potsdam, Germany. 
OceanObs'19, 2019. Recommendations from OceanObs'19 Conference, OceanObs'19, (56).

Okal, E., Fritz, H., \& Sladen, A., 2009. 2004 Sumatra-Andaman tsunami surveys in the Comoro Islands and Tanzania and regional tsunami hazard from future Sumatra events, South African Journal of Geology, 112(3-4), 343-358.

Okal, E. A. \& Reymond, D., 2003. The mechanism of great Banda Sea earthquake of 1 February 1938: Applying the method of preliminary determination of focal mechanism to a historical event, Earth and Planetary Science Letters, 216(1-2), $1-15$.

Okal, E. A. \& Synolakis, C. E., 2004. Source discriminants for near-field tsunamis, Geophysical Journal International, 158(3), 899-912.

Okal, E. A. \& Synolakis, C. E., 2008. Far-field tsunami hazard from mega-thrust earthquakes in the Indian Ocean, Geophysical journal international, 172(3), 9951015.

Okal, E. A., Fritz, H. M., Raad, P. E., Synolakis, C., Al-Shijbi, Y., \& Al-Saifi, M., 2006a. Oman field survey after the December 2004 Indian Ocean tsunami, Earthquake Spectra, 22(S3), 203-218.

Okal, E. A., Fritz, H. M., Raveloson, R., Joelson, G., Pančošková, P., \& Rambolamanana, G., 2006b. Madagascar field survey after the December 2004 Indian Ocean tsunami, Earthquake Spectra, 22(3_suppl), 263-283.

Permana, H. \& Singh, C., 2016. Submarine landslide and localized tsunami potentiality of Mentawai Basin, Sumatra, Indonesia, Bulletin of the Marine Geology, 23(1), $1-8$.

Petersen, M. D., Dewey, J., Hartzell, S., Mueller, C., Harmsen, S., Frankel, A., \& 
Rukstales, K., 2004. Probabilistic seismic hazard analysis for Sumatra, Indonesia and across the Southern Malaysian Peninsula, Tectonophysics, 390(1-4), 141-158.

Plafker, G., 2007. New evidence for a secondary tectonic source for the cataclysmic tsunami of 12/26/2004 on NW Sumatra.

Prior, D. B., Bornhold, B. D., Coleman, J. M., \& Bryant, W. R., 1982. Morphology of a submarine slide, Kitimat Arm, British Columbia, Geology, 10(11), 588-592.

Rabinovich, A. B., Thomson, R. E., \& Stephenson, F. E., 2006. The Sumatra tsunami of 26 December 2004 as observed in the North Pacific and North Atlantic oceans, Surveys in geophysics, 27(6), 647-677.

Rabinowitz, N., 2000. Hypocenter location using a constrained nonlinear simplex minimization method, in Advances in Seismic Event Location, pp. 23-49, Springer.

Ruhl, C., Melgar, D., Grapenthin, R., \& Allen, R., 2017. The value of real-time GNSS to earthquake early warning, Geophysical Research Letters, 44(16), 8311-8319.

Sakya, A. E., 2020. Review on research effort for (Indonesia) tsunami early warning, $45^{\text {th }}$ Pertemuan Ilmiah Tahunan Himpunan Ahli Geologi Indonesia (PIT HAGI), 20 September 2020.

Salaree, A., 2019. Theoretical and computational contributions to the modeling of global tsunamis, PhD Dissertation, Northwestern University, 359p.

Salaree, A. \& Okal, E. A., 2015. Field survey and modelling of the Caspian Sea tsunami of 1990 June 20, Geophys. J. Intl., 201(2), 621-639.

Salaree, A. \& Okal, E. A., 2020. Tsunami simulations along the Eastern African coast from mega-earthquake sources in the Indian Ocean, Arabian Journal of Geosciences, $\mathbf{1 3}(20), 1-13$.

Salaree, A., Huang, Y., Ramos, M. D., \& Stein, S., 2021. Relative tsunami hazard 
from segments of Cascadia subduction zone for $M_{w}$ 7.5-9.2 earthquakes, Geophys. Res. Lett., [in review].

Saraò, A., Das, S., \& Suhadolc, P., 1998. Effect of non-uniform station coverage on the inversion for earthquake rupture history for a Haskell-type source model, Journal of Seismology, 2(1), 1-25.

Satake, K., 2014. Advances in earthquake and tsunami sciences and disaster risk reduction since the 2004 Indian Ocean tsunami, Geoscience Letters, 1(1), 15.

Schäfer, A. M. \& Wenzel, F., 2019. Global megathrust earthquake hazard-maximum magnitude assessment using multi-variate machine learning, Frontiers in Earth Science, 7, 136.

Schmitt, R. G., Tanyas, H., Jessee, M. A. N., Zhu, J., Biegel, K. M., Allstadt, K. E., Jibson, R. W., Thompson, E. M., van Westen, C. J., Sato, H. P., et al., 2020. An open repository of earthquake-triggered ground-failure inventories (ver. 3, September 2020), Tech. rep., US Geological Survey, [accessed on 14 Dec 2020].

Setiyono, U., Gusman, A. R., Satake, K., \& Fujii, Y., 2017. Pre-computed tsunami inundation database and forecast simulation in Pelabuhan Ratu, Indonesia, Pure and Applied Geophysics, 174(8), 3219-3235.

Shuto, N., Suzuki, T., \& Hasegawa, K., 1986. A study of numerical techniques on the tsunami propagation and run-up, Science of Tsunami Hazard, 4, 111-124.

Skempton, A., 1953. Soil mechanics in relation to geology, Proceedings of the Yorkshire Geological Society, 29(1), 33-62.

Steketee, J., 1958. Some geophysical applications of the elasticity theory of dislocations, Canadian Journal of Physics, 36(9), 1168-1198.

Sweet, S. \& Silver, E., 2003. Tectonics and slumping in the source region of the 1998 
Papua New Guinea tsunami from seismic reflection images, in Landslide Tsunamis: Recent Findings and Research Directions, pp. 1945-1968, Springer.

Synolakis, C., Okal, E., \& Bernard, E., 2005. The megatsunami of December 26, 2004, The Bridge, 35(2), 26.

Synolakis, C. E., 2003. Tsunami and seiche, in: Earthquake Engineering Handbook, pp. 9_1-9_90.

Synolakis, C. E. \& Kong, L., 2006. Runup measurements of the December 2004 Indian Ocean tsunami, Earthquake Spectra, 22(3_suppl), 67-91.

Synolakis, C. E., Bardet, J.-P., Borrero, J. C., Davies, H. L., Okal, E. A., Silver, E. A., Sweet, S., \& Tappin, D. R., 2002. The slump origin of the 1998 Papua New Guinea tsunami, 458(2020), 763-789.

Synolakis, C. E., Bernard, E. N., Titov, V. V., Kânoğlu, U., \& González, F. I., 2008. Validation and verification of tsunami numerical models, in Tsunami Science Four Years after the 2004 Indian Ocean Tsunami, pp. 2197-2228, Springer.

Tappin, D., McNeil, L., Henstock, T., \& Mosher, D., 2007. Mass wasting processesoffshore Sumatra, in Submarine Mass Movements and Their Consequences, pp. 327-336, Springer, Eds. V. Lykousis, D. Sakellariou and J. Locat.

TeleGeography, 2020. Submarine Cable Map, PriMetrica Inc., https://www. submarinecablemap.com, accessed in Aug 2020.

Thingbaijam, K. K. S., Martin Mai, P., \& Goda, K., 2017. New empirical earthquake source-scaling laws, Bulletin of the Seismological Society of America, 107(5), 22252246.

Thurber, C. H. \& Engdahl, E. R., 2000. Advances in global seismic event location, in Advances in seismic event location, pp. 3-22, Springer. 
Titov, V., Rabinovich, A. B., Mofjeld, H. O., Thomson, R. E., \& González, F. I., 2005.

The global reach of the 26 December 2004 Sumatra tsunami, Science, 309(5743), $2045-2048$.

Titov, V., Kânoğlu, U., \& Synolakis, C., 2016. Development of MOST for real-time tsunami forecasting, Journal of Waterway, Port, Coast and Oceanic Engineering, 142, 03116004-1-03116004-16.

Tsimopoulou, V., Mikami, T., Hossain, T. T., Takagi, H., Esteban, M., Utama, N. A., et al., 2020. Uncovering unnoticed small-scale tsunamis: Field survey in Lombok, Indonesia, following the 2018 earthquakes, Natural Hazards: Journal of the International Society for the Prevention and Mitigation of Natural Hazards, pp. $1-26$.

Ward, S. N., 2001. Landslide tsunami, Journal of Geophysical Research: Solid Earth, 106(B6), 11201-11215.

Wessel, P. \& Smith, W. H., 1998. New, improved version of Generic Mapping Tools released, Eos, Transactions American Geophysical Union, 79(47), 579-579.

Widiyantoro, S., Gunawan, E., Muhari, A., Rawlinson, N., Mori, J., Hanifa, N., Susilo, S., Supendi, P., Shiddiqi, H., Nugraha, A., et al., 2020. Implications for megathrust earthquakes and tsunamis from seismic gaps south of Java Indonesia, Scientific reports, 10(1), 1-11.

Williamson, A., Melgar, D., \& Rim, D., 2019. The effect of earthquake kinematics on tsunami propagation, Journal of Geophysical Research: Solid Earth, 124(11), 11639-11650.

WorldBank, 2017. Indonesia - Small Hydro GIS Atlas, Energy Sector Management Assistance Program (ESMAP), https://energydata.info/dataset/ indonesia-small-hydro-gis-database-2017. 
Wysession, M. E., Okal, E. A., \& Miller, K. L., 1991. Intraplate seismicity of the Pacific Basin, 1913-1988, Pure and Applied Geophysics, 135(2), 261-359.

Yang, X., Singh, S. C., \& Tripathi, A., 2020. Did the Flores backarc thrust rupture offshore during the 2018 Lombok earthquake sequence in Indonesia?, Geophysical Journal International, 221(2), 758-768.

Ye, L., Lay, T., Kanamori, H., Yamazaki, Y., \& Cheung, K. F., 2021. The 22 July $2020 M_{w}$ 7.8 Shumagin seismic gap earthquake: Partial rupture of a weakly coupled megathrust, Earth and Planetary Science Letters, 562, 116879.

Yeh, H., Imamura, F., Synolakis, C., Tsuji, Y., Liu, P., \& Shi, S., 1993. The Flores Island tsunamis, Eos, Transactions American Geophysical Union, 74(33), 369-373.

Zollo, A., Lancieri, M., \& Nielsen, S., 2006. Earthquake magnitude estimation from peak amplitudes of very early seismic signals on strong motion records, Geophysical Research Letters, $\mathbf{3 3}(23)$. 